\title{
Impact of North Atlantic Current changes on the Nordic Seas and the Arctic Ocean
}

\author{
Frank Kauker, ${ }^{1}$ Rüdiger Gerdes, Michael Karcher, ${ }^{1}$ and Cornelia Köberle \\ Alfred Wegener Institute for Polar and Marine Research, Bremerhaven, Germany \\ Received 26 July 2004; revised 27 June 2005; accepted 11 August 2005; published 2 December 2005.
}

[1] The impact of North Atlantic Current (NAC) volume, heat, and salt transport variability onto the Nordic Seas and the Arctic Ocean is investigated using numerical hindcast and sensitivity experiments. The ocean-sea ice model reproduces observed propagation pathways and speeds of SST anomalies. Signals reaching the entrance to the Nordic Seas between Iceland and Scotland originate partly in the lower-latitude North Atlantic. Response experiments with different prescribed conditions at $50^{\circ} \mathrm{N}$ show that changes in the barotropic flow across $50^{\circ} \mathrm{N}$ have no impact on the seas north of the Greenland-Scotland Ridge because of the strong deformation of the $\mathrm{f} / \mathrm{H}$ field. A temperature anomaly inserted in the upper $500 \mathrm{~m}$ at $50^{\circ} \mathrm{N}$, on the other hand, has a widespread effect on the temperature distribution and the circulation in the high-latitude North Atlantic. NAC induced variability in the Nordic Seas and locally induced variability have similar magnitude. The local atmospheric influence and the complexity of North Atlantic-Nordic Seas advection pathways make it unlikely that detection of signal propagation in the NAC could lead to a prediction of oceanic conditions in the Nordic Seas and the Arctic Ocean with several years lead time.

Citation: Kauker, F., R. Gerdes, M. Karcher, and C. Köberle (2005), Impact of North Atlantic Current changes on the Nordic Seas and the Arctic Ocean, J. Geophys. Res., 110, C12002, doi:10.1029/2004JC002624.

\section{Introduction}

[2] The increasingly positive state of the North Atlantic Oscillation (NAO) over the last 3 to 4 decades enhances the wind stress forcing of the subpolar gyre [Hurrell, 1995], while larger heat losses over the Labrador Sea enhance deep water production there [Dickson et al., 1996; Gerdes et al., 2005]. Both the wind stress and the thermohaline forcing affect the North Atlantic Current (NAC). The NAC is a major source of heat for the Arctic Ocean and the Nordic Seas. The salt provided by the NAC makes possible the production of dense water on the Arctic shelves and in the Greenland Sea [Mauritzen, 1996].

[3] The circulation system of the Nordic Seas has recently been described by Hansen and Østerhus [2000]. A map showing main topographic features and schematic currents is displayed in Figure 1. A branch of the NAC enters the Nordic Seas between Iceland and Scotland and forms the Norwegian-Atlantic Current (NwAC). The NwAC divides into a branch that recirculates in the Nordic Seas and two branches that continue into the Arctic Ocean, the Fram Strait branch and the Barents Sea branch.

[4] The volume transport variability of the eastern branch of the NwAC has been found to be linked to the zonally averaged wind-stress curl at about $55^{\circ} \mathrm{N}$ over the eastern

\footnotetext{
${ }^{1}$ Also at O.A.Sys, Ocean Atmosphere System, Hamburg, Germany.
}

Copyright 2005 by the American Geophysical Union. 0148-0227/05/2004JC002624\$09.00
North Atlantic on interannual timescales [Orvik and Skagseth, 2003]. Karcher et al. [2003] and Ingvaldsen et al. [2004] find large inflow into the Barents Sea associated with intense cyclonicity of the wind field over the Norwegian Sea. Interannual temperature and salinity fluctuations in the NwAC have amplitudes of $1-2^{\circ} \mathrm{C}$ and 0.05 , respectively. The anomalies are partially advected from the IcelandScotland Ridges and partially locally generated in the Nordic Seas [Furevik, 2001; Saloranta and Haugan, 2001]. The latter holds especially for the anomalously warm events of the 1990s [Karcher et al., 2003; Gerdes et al., 2003]. A prominent example for an anomaly which has been advected across the ridges into the Nordic Seas is the returning signal of the Great Salinity Anomaly from the 1970s after circulating the subpolar gyre from Denmark Strait to the FaroerScotland area [Dickson et al., 1988].

[5] The NAC and the NwAC are important sources of heat and salt for the region and conceivably important sources of long-term variability in the oceanic and sea ice conditions. However, long-term changes in atmospheric forcing over the Nordic Seas might be as important as any signal advected from the subpolar North Atlantic [Dickson et al., 1996].

[6] Here, we show how fluctuations in volume transport, temperature, and salinity of the NAC affect the variability of ocean-sea ice conditions in the Nordic Seas and the Arctic Ocean. We start in the following section with a description of the numerical experiments employed in this study. The propagation of SST signals in two models differing in resolution and computational domain is investigated in 


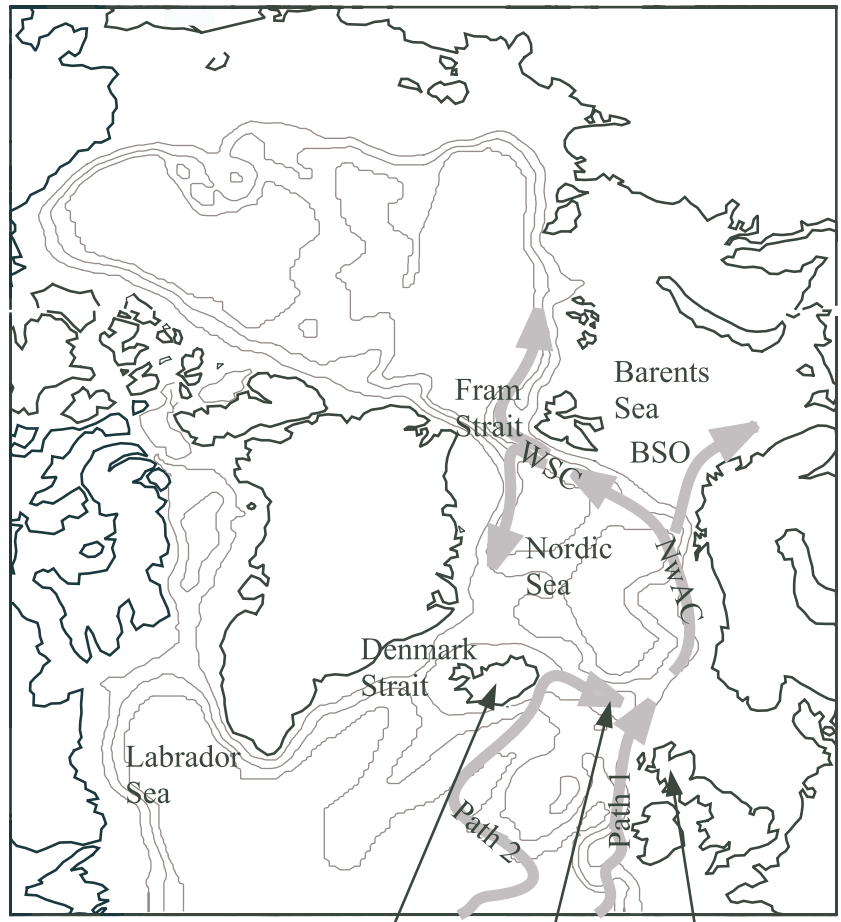

Iceland Faroer Scotland

Figure 1. A map showing main topographic features and schematic currents relevant for this study. Abbreviations: NwAC - Norwegian Atlantic Current, WSC - West Spitsbergen Current, BSO - Barents Sea Opening. Path1 and path 2 are the eastern and western branches of Atlantic Water inflow into the Nordic Seas mentioned in the text.

section 3 , followed by the presentation of results from the sensitivity experiments in section 4. A summary of the results and the major conclusions are given in section 5 .

\section{Goals and Methods}

[7] This study specifically addresses the consequences of fluctuations in the transports of volume, heat, and salt of the NAC for the circulation and the hydrographic and sea ice conditions in the Nordic Seas and the Arctic Ocean. These changes induced by upstream current variability have to be distinguished from those changes induced by variability of the local atmospheric forcing. Depending on the relative contribution of advective signals transported with the NAC into the Nordic Seas and the local forcing, there is a potential for predicting the variability in the Nordic Seas. However, even if the advective contribution is large and thus the potential predictability high, measuring the relevant upstream signals might be nontrivial and defy traditional approaches to measure these signals.

[8] We tackle these questions with experiments using coupled ocean-sea ice models of the NAOSIM (North Atlantic/Arctic Ocean-Sea Ice Model) hierarchy of the Alfred Wegener Institute (AWI). The two models considered here differ mainly in the spatial resolution and the model domain.

[9] The ocean circulation model derives from the GFDL modular ocean model (MOM-2) [Pacanowski, 1995]. For the advection of potential temperature, salinity, and other tracers a flux-corrected transport (FCT) scheme [Zalesak, 1979; Gerdes et al., 1991] is employed. A dynamicthermodynamic sea-ice model of the Hibler type [Hibler, 1979; Harder et al., 1998] is coupled to the ocean model.

[10] The first model of the hierarchy (called LRM (LowResolution Model)) has a horizontal resolution of approximately $100 \mathrm{~km}\left(1^{\circ} \times 1^{\circ}\right)$ and 19 unevenly spaced levels in the vertical. The model domain contains the Arctic Ocean, the Nordic Seas, and the Atlantic north of $20^{\circ} \mathrm{S}$. The model is formulated on a spherical grid that is rotated such that geographical $30^{\circ} \mathrm{W}$ meridian becomes the equator of the grid while the Pole is situated at $60^{\circ} \mathrm{E}$ on the geographical equator. The models southern boundary is here implemented as a solid wall. The model is forced with daily atmospheric wind stress and 2-m temperature data of the NCEP/NCAR reanalysis [Kalnay et al., 1996] for the period 1958 to 1997. All other atmospheric forcing data are monthly NCEP/NCAR reanalysis climatologies. A detailed description of the LRM and the atmospheric forcing can be found in the work of Köberle and Gerdes [2003].

[11] Results from the LRM are used to describe propagating surface temperature signals in the North Atlantic. It also provides lateral boundary conditions for the second model.

[12] The second model (called HRM (High-Resolution Model)) has a horizontal resolution of approximately $28 \mathrm{~km}$ $\left(1 / 4^{\circ} \times 1 / 4^{\circ}\right)$ and 30 unevenly spaced levels in the vertical. The model domain encompasses the Arctic Ocean, the Nordic Seas, and most of the subpolar North Atlantic north of approximately $50^{\circ} \mathrm{N}$. The HRM is documented in several publications [Gerdes et al., 2001; Karcher et al., 2003; Kauker et al., 2003]. Results from the HRM are used to describe propagating signals in the Nordic Seas and the HRM is used for the sensitivity experiments described below.

[13] The horizontal grid is rotated in the same way as in the LRM. At the southern boundary an open boundary condition has been implemented following Stevens [1991], allowing the outflow of tracers and the radiation of waves. At inflow points temperature and salinity are restored with a time constant of 50 days toward an annual mean climatology [Levitus et al., 1994]. The baroclinic part of the horizontal velocity is calculated from a simplified momentum balance. The momentum equation is simplified by omitting the nonlinear momentum advection. The barotropic velocities normal to the boundary are specified from the LRM model because no appropriate observations exist. The other boundaries are treated as closed walls.

[14] Two atmospheric data sets are used to force the HRM. Röske [2001] compiled climatological monthly means from the ECMWF reanalysis to which the daily variability from a selected year (1982) is added. This data set is utilized for most of the experiments performed in this study and for the spinup of the HRM. The second data set used is the NCEP/NCAR reanalysis for the period 1948 to 2002.

\section{Propagating Signals in Hindcast Experiments}

[15] We first show that the NAOSIM models are able to reproduce the observed long-distance propagation of temperature anomalies. The models are forced with the 2-m air 

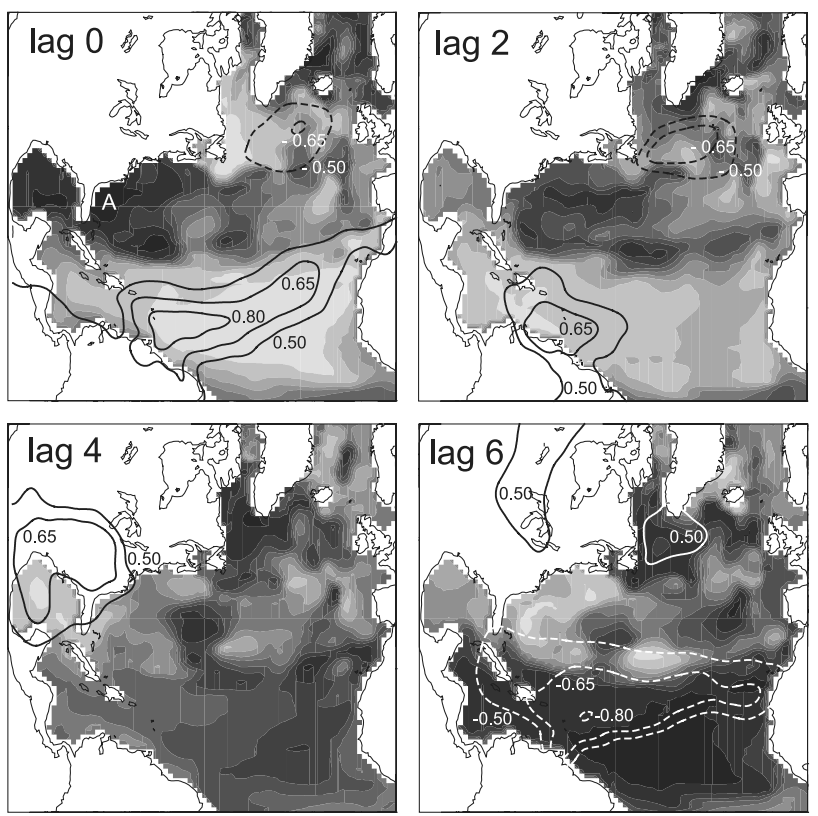

$\begin{array}{lllllllllll}-1.0 & -0.8 & -0.6 & -0.4 & -0.2 & 0.0 & 0.2 & 0.4 & 0.6 & 0.8 & 1.0\end{array}$

Figure 2. The amount of low-frequency variability of local sea-surface temperature (SST) and sea-level pressure (SLP) that can be accounted for as a linear response to the SST off the coast of Florida. The SST off the coast of Florida leads the local SST and the local SLP by the amount of years indicated in each panel. The contour lines shown for the SLP regression are for $\pm 0.50, \pm 0.65$, and \pm 0.80 . Dashed lines indicate negative correlations. Note the locations "A" off Florida in the upper left panel (see text). See color version of this figure at back of this issue.

temperature in the sense that heat fluxes are calculated from bulk formulas where the difference of the 2-m air temperature and the predicted SST enter. This provides a strong damping of SST anomalies internally generated by the model. Figure 2 shows the propagation of SST anomalies in the LRM under NCAR/NCEP forcing. Our analysis follows that of Sutton and Allen [1997], who analyzed observational data: area-averaged SST anomalies in the latitude-longitude box $25-35^{\circ} \mathrm{N}, 82-69^{\circ} \mathrm{W}$ off the coast of Florida (called Storm Formation Region (SFR); label "A," Figure 2, lag 0) were calculated for the winter season (defined as the months November to March). Then, a 5-year running mean is applied and the resulting time series is detrended. The time series has amplitudes of the order of $0.2-0.4^{\circ} \mathrm{C}$. The (filtered and detrended) modeled local SST in the North Atlantic/Nordic Seas is regressed upon the SFR time series.

[16] Figure 2 depicts the correlation coefficients between the SFR time series and SST for time lags of $0,2,4$, and 6 years. Also shown are the correlation coefficients with the SLP. As argued by Sutton and Allen [1997] (and confirmed by our simulation, no results shown), these SLP anomalies are associated with wind stress anomalies at the northwestern coast of Africa which set up Rossby wave-like propagation of SST anomalies from the eastern boundary and low-latitude North Atlantic into the Gulf of Mexico. Then, these SST anomalies propagate eastward and northward through the passage between Cuba and Florida. The SST anomalies off the coast of Florida propagate along the Gulf Stream/NAC pathway, as analyzed by Sutton and Allen [1997] and simulated by the model.

[17] In addition, the model reveals that simultaneously with the SST anomalies in the SFR, SST anomalies appear north of Iceland. These anomalies follow the East and West Greenland Currents into the Labrador Sea and merge with the SST anomalies coming from the SFR in the northwestern North Atlantic after about 4 years. After 6 years the temperature anomalies have reached the Iceland-Scotland ridge. Although the analysis of the model results suggest a somewhat different interpretation than provided by Sutton and Allen [1997], the propagation of SST anomalies in the model is similar with respect to pathways, amplitude, and travel times.

[18] An experiment with the HRM, forced with the NCEP/NCAR reanalysis for the period 1948 to 2002 (with fixed conditions at the southern boundary), shows the propagation of temperature anomalies related to the NAO in the Nordic Seas and the Arctic Ocean. In contrast to the SFR related variability, we utilized the HRM for the discussion on the NAO related variability. This will allow us to assess the variability which is entirely generated due to the atmospheric surface forcing within the HRM domain. In chapter 4 this NAO related variability will be compared to the variability induced at the southern boundary.

[19] Positive temperature anomalies evolve simultaneously around Ireland, in the North Sea, along the Norwegian coast, and in the Barents Sea with a positive anomaly of the NAO (Figure 3, lag 0) due to local air-sea interaction, based on the monthly NAO index of Jones et al. [1997]. The regression is performed with detrended mean data of the winter months December to March. Only changes with a correlation higher than 0.4 are shown. These anomalies are found significant at the $90 \%$ level with a Monte Carlo method, fitting an AR(1) processes to the NAO time series. Part of these anomalies can be traced for three consecutive winters on their pathways, for instance, from the Barents Sea into the Kara Sea, and also the recirculating branch of the West Spitsbergen Current into the Nordic Seas can be seen. The fact that these anomalies can be traced at least for a period of 3 years demonstrates that they are dominantly of advective character.

[20] For comparison with the upcoming sensitivity experiments, we calculated the upper $300 \mathrm{~m}$ heat content associated with the NAO in a box following the NwAC in the Nordic Seas where the strongest NAO related signals occur (see label "A" in Figure 3, lag 3). Both the heat content time series and the NAO index were taken for December through March and detrended. The resulting time series are correlated such that a change of the NAO index of one standard deviation is associated with a change in the heat content of $1.16 \cdot 10^{20} \mathrm{~J}$. This corresponds to a change of the mean temperature in the box of about $0.12^{\circ} \mathrm{C}$ (see Figure 4).

[21] The heat content in box A follows the NAO not strictly. The first 20 years are only weakly correlated but since the winter 1968-1969 the heat content and the NAO are well correlated $(r=0.5)$. However, the differences in 

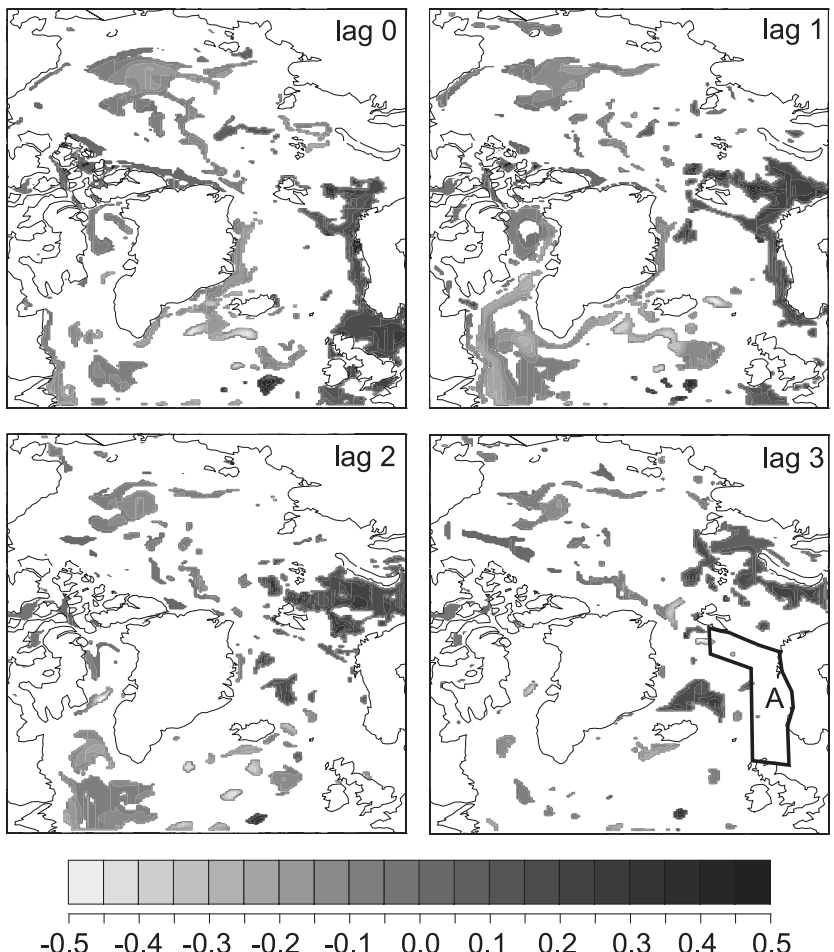

$\begin{array}{lllllllllll}-0.5 & -0.4 & -0.3 & -0.2 & -0.1 & 0.0 & 0.1 & 0.2 & 0.3 & 0.4 & 0.5\end{array}$

Figure 3. The averaged temperature $\left[{ }^{\circ} \mathrm{C}\right]$ of the upper $300 \mathrm{~m}$ water column which can be accounted for as a linear response to the NAO. The NAO leads the local temperature by the amount of years shown in each plot. Only significant (correlation coefficient higher than 0.4) slope coefficients are displayed. Note the locations of box "A" off the Norwegian coast and south of Spitsbergen in the lower right panel (see text). See color version of this figure at back of this issue.

heat content between the winter $1968-1969$ with a very low NAO index of about -5 and the winter 1988-1989 with an extremely high index of about +5 are remarkable. The heat content difference between these winters follows the NAO nicely with a time lag of 1 year and amounts to about 10 . $10^{20} \mathrm{~J}$ which corresponds to a mean temperature change in the box of about $1^{\circ} \mathrm{C}$ (see Figure 4). Other events, like the strong drop of the NAO following the high NAO winter 1994-1995 shows only weak response in the heat content.

[22] The peak-to-peak anomalies of the winter mean salinity in box A amount to $0.08 \mathrm{psu}$. In contrast to the heat content, the salt content in box A shows no significant correlation with the NAO.

[23] The instantaneous response to the NAO is due to anomalous local surface heat fluxes and anomalous ocean heat transport convergence generated in the model domain. Table 1 lists the mean, the standard deviation, and the correlation with the NAO of the northward wintertime volume, heat, and salt transports through the FaroerScotland ridge, the Iceland-Faroer ridge, the Barents Sea Opening (BSO), and the Fram Strait for the NCEP/NCAR run with the HRM. The open boundary conditions at the southern boundary of the model neither provide barotropic volume transport variability nor changes of the inflowing water masses. Nevertheless, considerable baroclinic fluctuations of volume, heat, and salt transport are found. The transports of volume, heat, and salt at the southern boundary

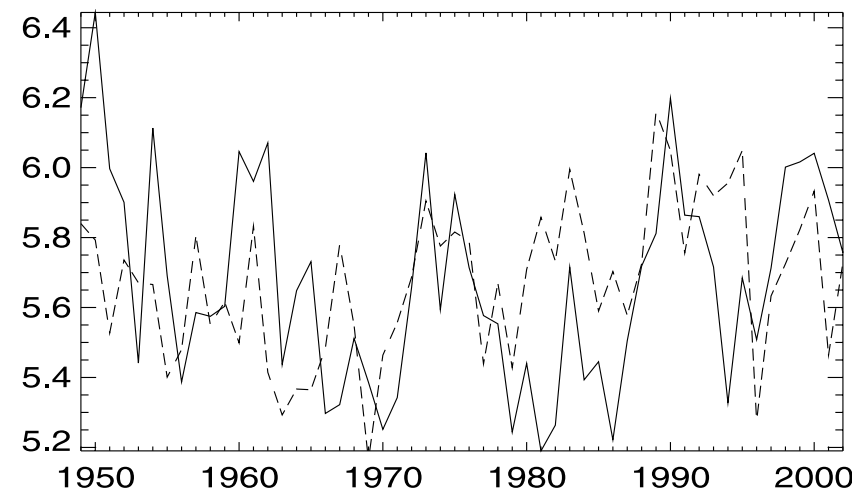

Figure 4. The averaged temperature $\left[{ }^{\circ} \mathrm{C}\right]$ of the upper $300 \mathrm{~m}$ water column in box " $\mathrm{A}$ " (solid) and the NAO time series (dashed). Note that the NAO time series is rescaled to match the range of the averaged temperature.

are independent of the NAO with correlation coefficients of below 0.11 . On the other hand, the transports through the Faroer-Scotland ridge are highly correlated with the NAO. From this we conclude that the variability at the southern boundary is not the source of the temperature anomalies shown in Figure 3.

[24] The anomalies shown in Figure 3 are mainly produced in winter and extend over the deep winter mixed layer. In summer the anomalies are insulated from the atmosphere by a shallow mixed layer. They are reentrained when the mixed layer deepens again in fall and winter. This reemergence mechanism was originally described by Timlin et al. [2002]. The mechanism explains the persistence of these anomalies for several years.

[25] Both analyses presented, the temperature anomalies related to the SST in the SFR and those related to the $\mathrm{NAO}$, document the existence of propagating signals in the simulations.

\section{Sensitivity Experiments}

[26] Before the sensitivity experiments are explained in detail, we will give a short introduction which experiments we performed (Table 2).

[27] A control experiment (NACctrl) is forced with a daily atmospheric climatology taken from Röske [2001]

Table 1. Mean and Standard Deviation of the Northward Volume, Heat, and Salt Transports Through Various Sections in Winter (DJFM) and the Correlation (r) With the (DJFM Mean Jones et al. [1997]) NAO for 1949 to $2002^{\mathrm{a}}$

\begin{tabular}{|c|c|c|c|c|c|c|c|c|c|}
\hline \multirow[b]{2}{*}{ Section } & \multicolumn{3}{|c|}{$\begin{array}{l}\text { Volume } \\
\text { Transport }\end{array}$} & \multicolumn{3}{|c|}{ Heat Transport } & \multicolumn{3}{|c|}{ Salt Transport } \\
\hline & $\begin{array}{c}\text { Mean, } \\
\text { Sv }\end{array}$ & $\begin{array}{l}\sigma \\
\text { Sv }\end{array}$ & $\mathrm{r}$ & $\begin{array}{c}\text { Mean, } \\
\text { TW }\end{array}$ & $\begin{array}{c}\sigma, \\
\text { TW }\end{array}$ & $\mathrm{r}$ & $\begin{array}{l}\text { Mean, } \\
\text { ktons/s }\end{array}$ & $\begin{array}{c}\sigma, \\
\text { ktons/s }\end{array}$ & $\mathrm{r}$ \\
\hline FAR/SCO & 4.38 & .95 & .80 & 149 & 32 & .81 & 2.08 & .42 & .80 \\
\hline ICE/FAR & 3.68 & .42 & .37 & 98 & 13 & .28 & 1.29 & .18 & .18 \\
\hline $\mathrm{BSO}$ & 3.42 & .74 & .57 & 58 & 16 & .50 & .62 & .16 & .48 \\
\hline FRAM & 3.39 & .73 & .50 & 30 & 9 & .50 & .00 & .19 & - \\
\hline
\end{tabular}

${ }^{\text {a }}$ The heat transport is calculated relative to a reference temperature of $0^{\circ} \mathrm{C}$ and the salt transport relative to a reference salinity of $34.8 \mathrm{psu}$. Listed are the values for the Faroer-Scotland ridge (FAR/SCO), the Iceland-Faroer ridge (ICE/FAR), the Barents Sea Opening (BSO) and Fram Strait (FRAM). The correlation coefficients in bold are significant at the $90 \%$ level. No correlation for the salt transport through Fram Strait is given because the reference salinity is too close to the in situ salinity in Fram Strait. 
Table 2. Survey of the Sensitivity Experiments

\begin{tabular}{|c|c|}
\hline Experiment & Deviation From Ctrl-run \\
\hline NACctrl & - \\
\hline NACctrl1d & Disturbed initial conditions ocean/sea ice \\
\hline NACpsi & Anomaly added to stream function at southern boundary (see Figure 7) \\
\hline NAC3psi & Three times anomaly added to stream function at southern boundary \\
\hline $\mathrm{NAC}+2 \mathrm{~K} 500 \mathrm{~m}$ & Temperature of the upper $500 \mathrm{~m}$ increased by $2{ }^{\circ} \mathrm{C}$ at southern boundary \\
\hline $\mathrm{NAC}+\mathrm{SFR}$ & Stream function, temperature, salinity, changed by +1 SFR related mode at southern boundary \\
\hline NAC-SFR & Stream function, temperature, salinity, changed by -1 SFR related mode at southern boundary \\
\hline NCEP+SFR & $\begin{array}{l}\text { Stream function, temperature, salinity, changed by }+1 \text { SFR related mode at southern boundary; } \\
\text { surface forcing NCEP/NCAR 1961-1965 }\end{array}$ \\
\hline NCEP-SFR & $\begin{array}{c}\text { Stream function, temperature, salinity, changed by }-1 \text { SFR related mode at southern boundary; } \\
\text { surface forcing NCEP/NCAR } 1982-1986\end{array}$ \\
\hline
\end{tabular}

and integrated for 120 years. All sensitivity experiments start from year 60 of the control experiment and use the same atmospheric forcing if not stated otherwise. The experiment NACctrlld is identical to NACCtrl, except of disturbed initial conditions to assess the internal variability. For the experiments NACpsi and NAC3psi the barotropic stream function at the southern boundary is changed by typical values derived from the NCEP/NCAR hindcast run with the LRM. In the experiment NAC+2K500m temperatures are increased at the southern boundary by $2^{\circ} \mathrm{C}$ over the upper $500 \mathrm{~m}$ of the water column. These experiments serve to assess basic changes in circulation and hydrography that might for instance be expected during prolonged periods of the positive state of the NAO.

[28] For the experiments NAC+SFR and NAC-SFR, temperature, salinity, and stream function at the southern boundary were changed according to actual anomalies as they occur in the LRM experiment. In addition, realistic NCEP/NCAR atmospheric forcing has been chosen for the experiments NCEP_SFR.

\subsection{NACctrl}

[29] The model is initialized with a climatology of temperature and salinity fields from a combination of EWG- and WOA data sets (for the polar ocean and for most of the Nordic Seas) [Environmental Working Group $(E W G), 1997]$ and the rest of the domain [Levitus et al., 1994], respectively. At the southern open boundary, temperature and salinity from Levitus et al. [1994] are prescribed. The stream function at the lateral boundary is taken from the long-term mean (1958-1997) of the NCEP/ NCAR hindcast experiment with the LRM. Then, the model is integrated for 120 years.

[30] As a measure of (quasi-)stationarity in the Arctic and Nordic Seas time series of volume fluxes through the sections listed in Table 1 are displayed in Figure 5. The heat and salt transports show similar temporal variability (not shown). After about 60 years of spinup the most obvious oceanic adjustment ceases. The sensitivity experiments start from this state. However, interannual variability, most prominent at the southern boundary, across the Iceland-Faroer ridge and in Fram Strait, can be observed during the entire experiment. The mean (wintertime) volume, heat, and salt transports from year 60 to year 120 are comparable to $( \pm 2 \sigma)$ the NCEP/NCAR hindcast, i.e., the spinup has not drifted into an unrealistic state (see Table 1).

[31] While the adjustment of the large-scale hydrographic structures at $300 \mathrm{~m}$ depth has ceased at the end of year 60 of the spinup (not shown), interannual fluctuations of temperature with amplitudes of about $1{ }^{\circ} \mathrm{C}$ remain. Because the external forcing contains no interannual variability, the variability is internal to the ocean-sea ice system. To discriminate between the internal variability and the variability induced by the external forcing in the sensitivity experiments, the so-called $\Delta$-change approach is used [Gleick, 1986], i.e., changes in the sensitivity experiments will be discussed relative to the control experiment.

\subsection{NACctrl1d}

[32] Obviously, the internal variability in the HRM cannot be neglected. To obtain robust results, ensemble inte-
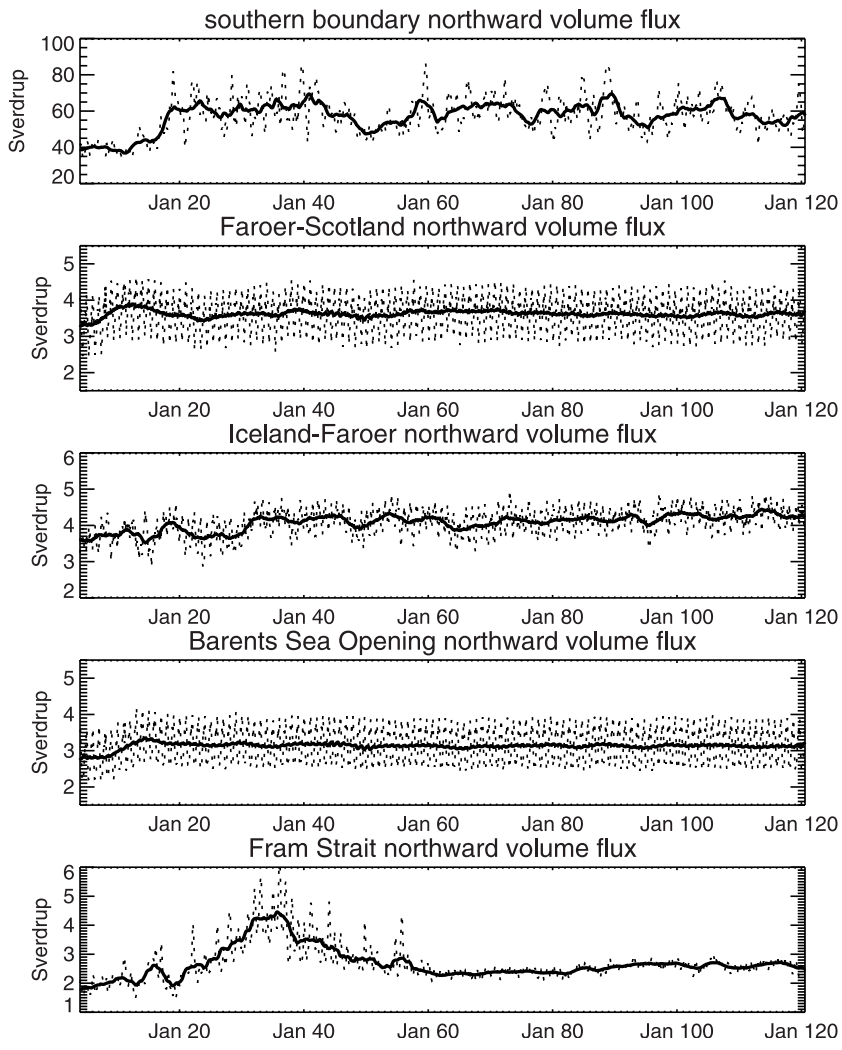

Figure 5. The northward volume transport [Sv] through the southern boundary, over the Faroer-Scotland ridge, over the Iceland-Faroer ridge, through the Barents Sea Opening, and through Fram Strait. Shown are monthly values (dashed line) for 120 years of spinup. Additionally, a 37-month running mean is plotted (thick line). 


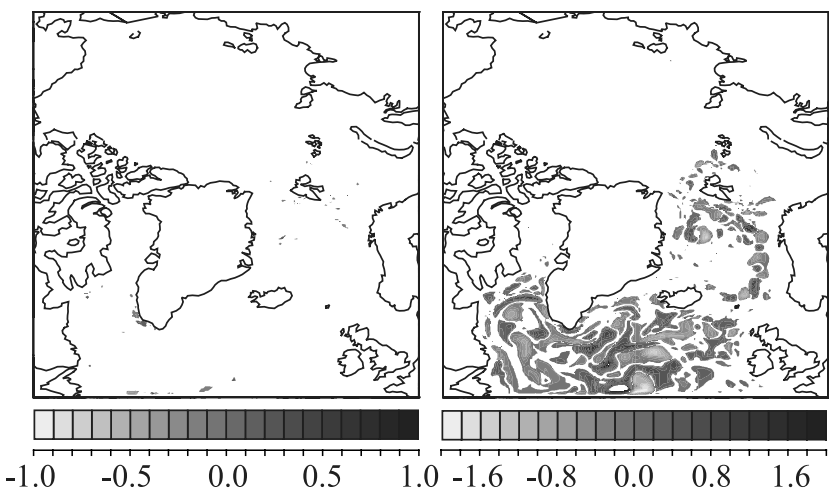

Figure 6. The temperature difference $\left[{ }^{\circ} \mathrm{C}\right]$ between NACctrlld and NACctrl at $300 \mathrm{~m}$ depth (left) after 5 months and (right) after 5 years of integration. Only differences larger than $0.1^{\circ} \mathrm{C}$ in magnitude are displayed. Note the different scales of the color bars. See color version of this figure at back of this issue.

grations would be desirable. However, the HRM is very expensive in terms of computer resources. Therefore to estimate the influence of internal variability, we performed only one integration with perturbed initial conditions of the ocean-sea ice system. The perturbation of the ocean-sea ice state was done by using the end of the first day of year 60 of the control run as the initial condition for NACctrlld.

[33] After 5 months of simulation only small deviations of the temperature at $300 \mathrm{~m}$ depth $\left(\mathrm{O}\left(0.1^{\circ} \mathrm{C}\right)\right)$ are noticeable between NACctrl1d and NACctrl (Figure 6, left). Without internal variability of the ocean-sea ice system, these differences should vanish while the simulation progresses. However, after 5 years the differences between both simulations have increased strongly (Figure 6, right). The amplitudes reach a few degrees $C$. Particularly large and spatially localized differences occur along the fronts in the eastern North Atlantic, in the Labrador Sea, the Nordic Seas, and north of Fram Strait. The barotropic stream function behaves similarly (not shown). After 5 years of simulation small-scale anomalies of more than $10 \mathrm{~Sv}$ emerge in the
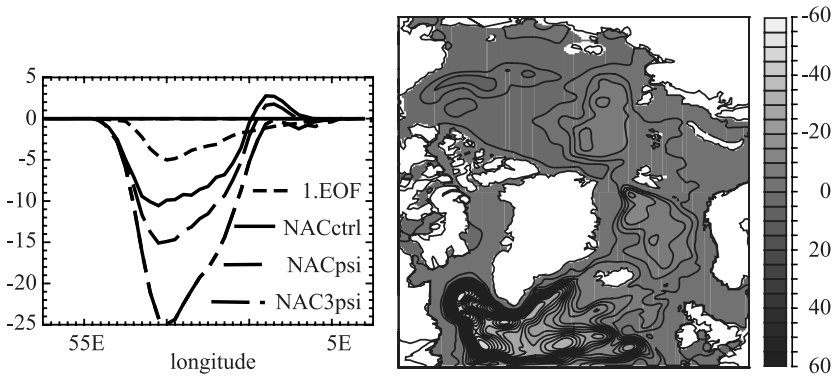

Figure 7. The mean state (right panel and the solid line in the left panel) of the barotropic stream function $[\mathrm{Sv}]$ in the control run and the first EOF (left panel short-dashed line) of the stream function at the southern boundary deduced from the NCEP/NCAR hindcast experiment with the LRM. Also the stream function at the southern boundary in experiment NACpsi (long-dashed line) and the experiment NAC3psi (long-short-long dashed line) are shown in the left panel. See color version of this figure at back of this issue.

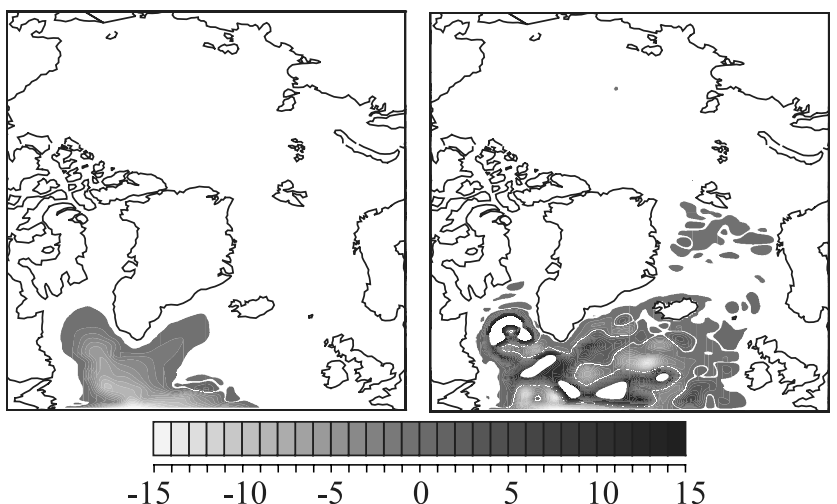

Figure 8. The difference of the stream function $[\mathrm{Sv}]$ between NAC3psi and NACctrl after 1 month (left) and after 5 years (right). Only differences larger than $0.1 \mathrm{~Sv}$ in magnitude are displayed. See color version of this figure at back of this issue.

eastern North Atlantic and the Labrador Sea, while the subpolar gyre has a strength of about $60 \mathrm{~Sv}$ in the mean.

[34] The differences are interpreted as instabilities associated with displacements of the main fronts in the ocean. These anomalies are time-dependent with timescales of some months and advect along the common pathways. It follows, that similar short-living, small-scale spatial structures in the sensitivity experiments cannot be interpreted as response to the introduced changes.

\subsection{NACpsi and NAC3psi}

[35] For NACpsi and NAC3psi we enhanced the exchange between the subpolar and subtropical domains by prescribing different distributions for the barotropic stream functions at the southern boundary. The mean distribution of the stream function at the southern boundary is taken from the NCAR/NCEP hindcast experiment with the LRM (Figure 7). The first EOF of the stream function at the southern boundary from the LRM is added in experiment NACpsi and three times the first EOF is added in experiment NAC3psi (Figure 7). Effectively, this enhances the
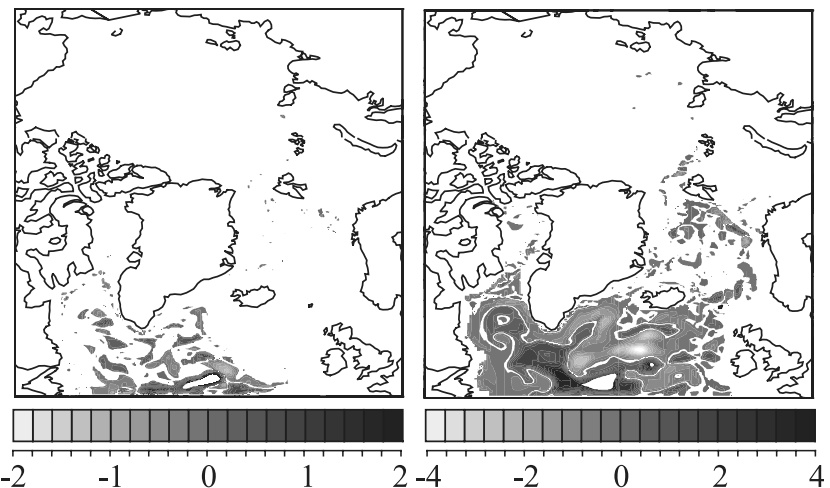

Figure 9. The difference of the temperature $\left[{ }^{\circ} \mathrm{C}\right]$ at $300 \mathrm{~m}$ depth between NAC3psi and NACctrl after 5 months (left) and after 5 years (right). Only differences larger than $0.1^{\circ} \mathrm{C}$ in magnitude are displayed. Note the different scales of the color bars. See color version of this figure at back of this issue. 


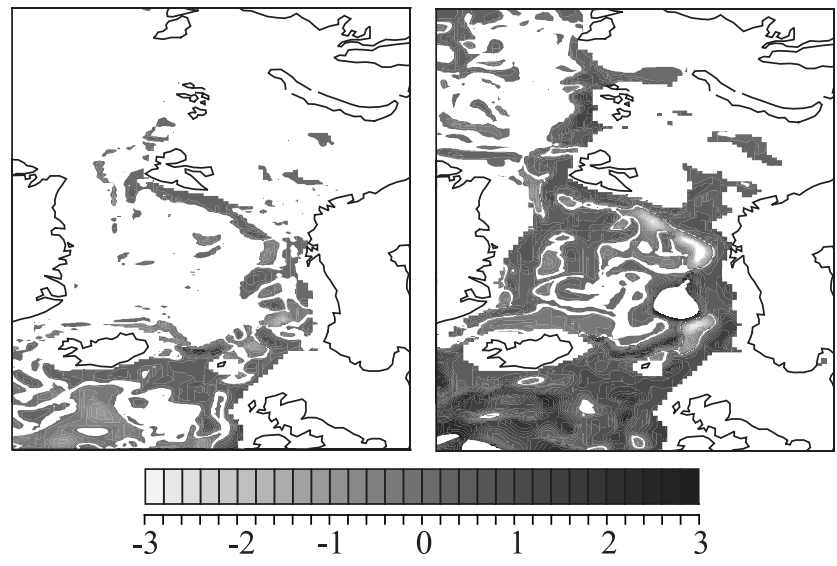

Figure 10. The difference of the temperature $\left[{ }^{\circ} \mathrm{C}\right]$ at $300 \mathrm{~m}$ depth between NAC $+2 \mathrm{~K} 500 \mathrm{~m}$ and NACctrl after 2 years (left) and after 5 years (right). Only differences larger than $0.1^{\circ} \mathrm{C}$ in magnitude are displayed. See color version of this figure at back of this issue.

broad northward barotropic flow of the westwind drift as well as the southward western boundary current. The results of both experiments are qualitatively similar. We thus restrict the following discussion to NAC3psi.

[36] The response to the changed stream function at the southern boundary after 1 month can be seen clearly in the subpolar gyre (Figure 8, left) which is strengthened in comparison to the control experiment. The adjustment is mainly due to Kelvin/topographic waves and ceases after a few days (not shown). However, after 5 years the subpolar gyre is actually weakened compared to the control experiment. Only small-scale differences can be found in the Nordic Seas. They are comparable to the internal variability (see NACCrtl1d) and thus not significant.

[37] The deviations of the temperature at $300 \mathrm{~m}$ depth after 5 months and 5 years, respectively, are depicted in Figure 9. After 5 months a tongue of anomalously warm water separates from the southern boundary. This anomaly never reaches the Nordic Seas. The anomalies in the Nordic Seas remain on a small spatial scale similar to those in NACctrlld (compare Figure 6). However, anomalies on the order of $4^{\circ} \mathrm{C}$ can be observed in the subpolar North Atlantic after 5 years of integration. The western part of the subpolar North Atlantic including the Labrador Sea has warmed considerably. The warming implies a reduction of the horizontal density gradients and a weakening of the cyclonic circulation. The advection of the warm anomaly by the initially enhanced subpolar gyre leads to its subsequent weakening. The prescribed stronger eastern inflow into the model domain is compensated by a return flow close to the southern model boundary.

\section{4. $\mathrm{NAC}+2 \mathrm{K500m}$}

[38] For this experiment the temperature of the upper $500 \mathrm{~m}$ of the water column is increased by $2^{\circ} \mathrm{C}$ at the southern boundary in experiment $\mathrm{NAC}+2 \mathrm{~K} 500 \mathrm{~m}$. Figure 10 depicts the changes of the temperature at $300 \mathrm{~m}$ depth relative to the control run at different stages of the adjustment. The temperature over the Iceland-Scotland ridge rises by about $0.5^{\circ} \mathrm{C}$ after 2 years. Also the Norwegian Current and the West Spitsbergen Current have warmed by a similar amount. After 2 years, the stream function shows enhanced cyclonic circulation in the North Atlantic (Figure 11). In the Greenland Sea and north of Fram Strait the cyclonic circulation increases by about $0.5 \mathrm{~Sv}$. Additional heat is carried with the NwAc and WSC (see Figure 10), thus increasing the horizontal density gradients in the upper part of the water column and speeding up the currents.

[39] Five years into the experiment, the temperature is significantly higher within the major currents, i.e., within the NwAC, WSC, and the Fram Strait branch of Atlantic inflow (Figure 10, right). Now, warming in the central Arctic Ocean is observable. The stream function in the subpolar Atlantic and the Nordic Seas disintegrates in smaller-scale features (Figure 11, right) as the changes in density become more widespread and are no longer restricted to the cores of the jets.

[40] The throughflows into the Nordic Seas show maximal change after about 1 to 3 years of integration. The northward volume transport over the Faroer-Scotland ridge is increased by about $1 \mathrm{~Sv}$ with respect to the control experiment which has a mean throughflow of about 3.7 Sv. This increase reduces into the experiment but the volume transport remains about $0.4 \mathrm{~Sv}$ higher over the rest of the experiment. Associated with the increased volume transport after 1 year is an about $50 \mathrm{TW}$ higher heat flux (relative to $0^{\circ} \mathrm{C}$ ) and an about 500 tons $/ \mathrm{s}$ higher salt transport (relative to $34.8 \mathrm{psu}$ ). The transports over the Iceland-Faroer ridge are changed by similar amounts but the maximal increases are reached in the years 2 to 3 of the experiment.

[41] The changes in SST (not shown) reflect the influence of the atmosphere on the propagating temperature anomalies. In summer, deviations are small compared to winter. The anomalies are damped in the relatively shallow mixed layer by surface fluxes. In winter they are reentrained as the mixed layer deepens.

[42] The heat content anomaly in box A in the Nordic Seas (compare Figure 3, lag 3) reaches $5.6 \cdot 10^{20} \mathrm{~J}$ after
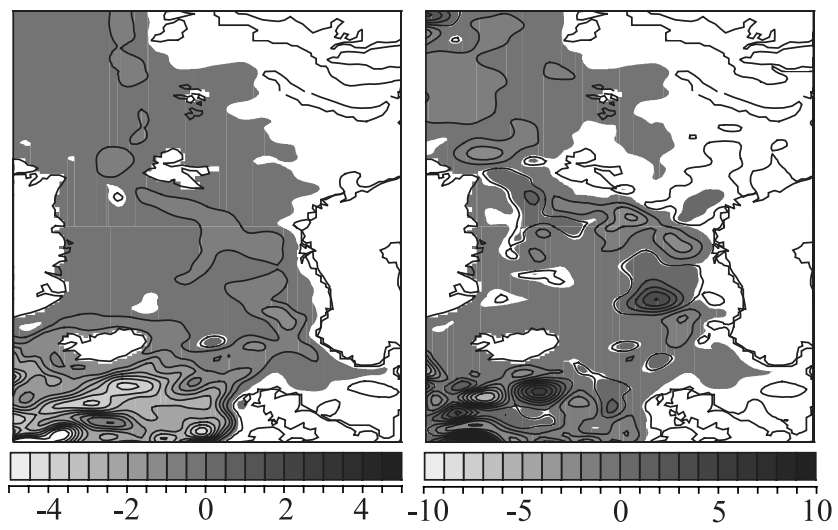

Figure 11. The difference of the stream function $[\mathrm{Sv}]$ for the vertically integrated volume transport between $\mathrm{NAC}+2 \mathrm{~K} 500 \mathrm{~m}$ and NACctrl (left) after 2 years and (right) after 5 years. Only differences larger than $0.1 \mathrm{~Sv}$ in magnitude are displayed. Additionally, on the left panel contours with an interval of $0.5 \mathrm{~Sv}$ and on the right panel with $1 \mathrm{~Sv}$ are plotted. Note the different scales of the color bars. See color version of this figure at back of this issue. 


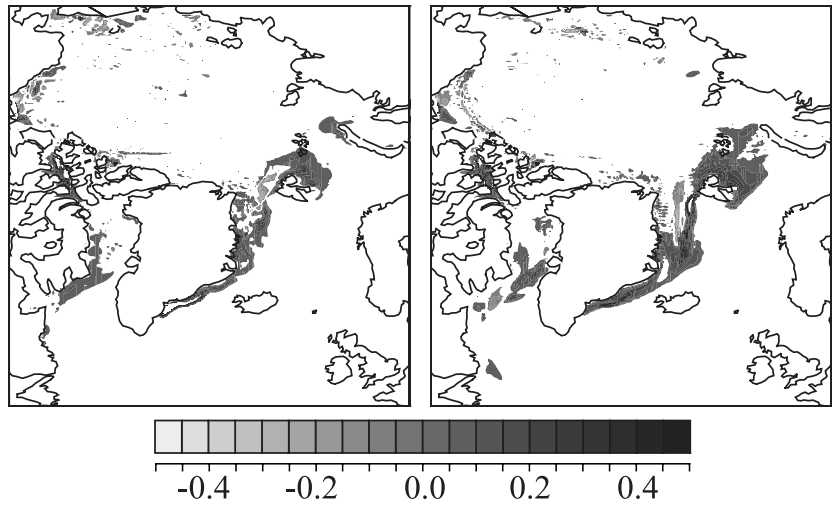

Figure 12. The difference in ice thickness $[\mathrm{m}]$ between $\mathrm{NAC}+2 \mathrm{~K} 500 \mathrm{~m}$ and NACctrl in summer after 4.5 years (left) and in the following winter. Only differences larger than $0.05 \mathrm{~m}$ in magnitude are displayed. See color version of this figure at back of this issue.

2 years integration. This corresponds to a mean temperature increase of about $0.55^{\circ} \mathrm{C}$. Although the imposed temperature anomaly of $2^{\circ} \mathrm{C}$ at the southern boundary is certainly higher as any recently observed anomaly at the location of the southern boundary, the anomalous heat content generated in this experiment is only half as high as the largest anomalies in the hindcast experiment (compare Figure 4).

[43] The sea ice reacts to the increased ocean temperature with a reduction of the sea ice thickness of about half a meter after 5 years integration in the Greenland Sea, north of Svalbard, and in the Irminger Sea (Figure 12). Although large temperature anomalies have passed Fram Strait at this time, no reduction of sea ice thickness in the central Arctic is visible. The temperature anomalies are confined to the Atlantic layer and the exchange of this layer with the mixed layer is obviously very low.

[44] Experiment NAC $+2 \mathrm{~K} 500 \mathrm{~m}$ shows that it is possible to induce temperature anomalies in the Nordic Seas and the Arctic Ocean by signal propagation from the subpolar grye. The deep-reaching anomalies can survive for several years despite the damping by the surface heat fluxes.

\subsection{NAC_SFR}

[45] In contrast to the previous experiments, NAC_SFR uses more realistic anomalies at the southern boundary. The anomalies were deduced from the NCAR/NCEP hindcast experiment with the LRM. To identify southern boundary conditions that yield largest heat transport anomalies into the Nordic Seas, we analyze the oceanic heat transport of the upper $250 \mathrm{~m}$ water column in a corridor between Scotland and Iceland with Empirical Orthogonal Functions and regression analysis using the corresponding principal components. Whereas the first two EOFs are associated with wind stress anomalies in the Nordic Seas and the subpolar Ocean, the third EOF is associated with wind stress anomalies in the tropical and subtropical Atlantic. The third EOF (describing 10.6\% of the variance) is statistically separated from the first two and fourth EOF according to North's rule of thumb [North et al., 1982]. The third EOF also has the strongest SST anomalies associated with it at the location of the southern boundary of the HRM. The time series of the third EOF (Figure 13a) shows exceptionally high values in the 1960 s, low values in the 1980 s, and increasing values in the 1990s. The vertical profiles of modeled temperature and salinity at the location of the southern boundary of the HRM have been regressed upon the third principal component. The derived temperature and salinity anomalies are added to (subtracted from) the mean temperature and salinity at the southern boundary (experiment NAC+SFR and experiment NAC-SFR, respectively; Figures $13 \mathrm{c}-13 \mathrm{f}$ ). Consequently, NAC+SFR is forced by boundary conditions typical for the hydrography of the 1960s and NAC-SFR such for the 1980s. The stream a)

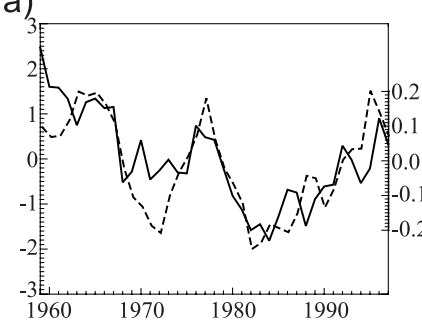

c)

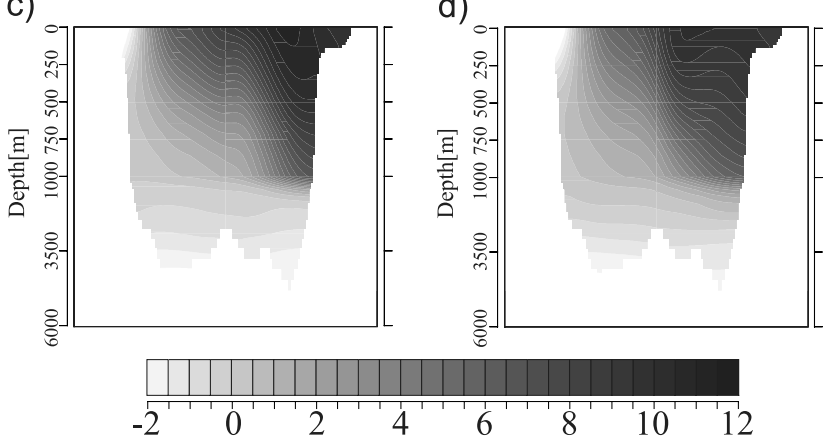

e)

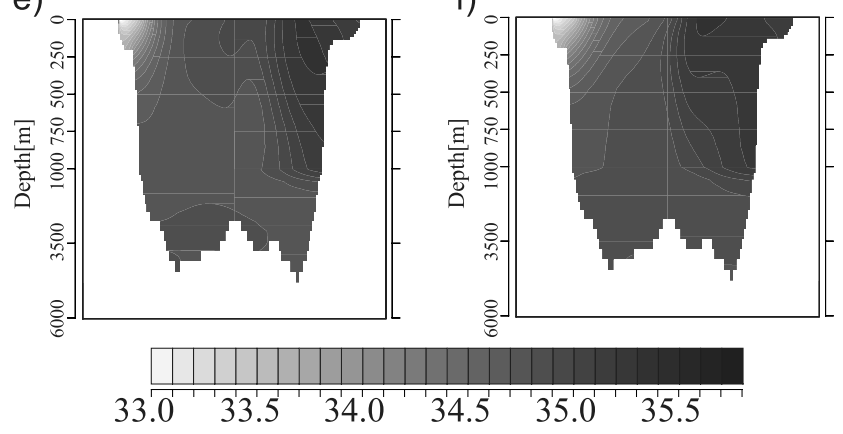

Figure 13. (a) The third principal component (solid line, left axis labels) of the heat transport in a corridor between Iceland and Scotland. Additionally, the time series of the winter-centered yearly mean observed SST $\left[{ }^{\circ} \mathrm{C}\right]$ in the SFR is shown (dashed line, right axis labels). The SFR time series is filtered with a 5-year running mean and shifted in time by 5 years, i.e., values from 1955 to 1993 are plotted, accounting for the travel time of the temperature signals. (b) The stream function for the experiments NAC+SFR and NAC-SFR and in the control run is shown [Sv]. The remaining panels show distributions at the southern boundary of the HRM of (c) temperature $\left[{ }^{\circ} \mathrm{C}\right]$ in experiment $\mathrm{NAC}+\mathrm{SFR}$, (d) NAC-SFR, (e) salinity [psu] in experiment NAC+SFR, and (f) NAC-SFR. See color version of this figure at back of this issue. 

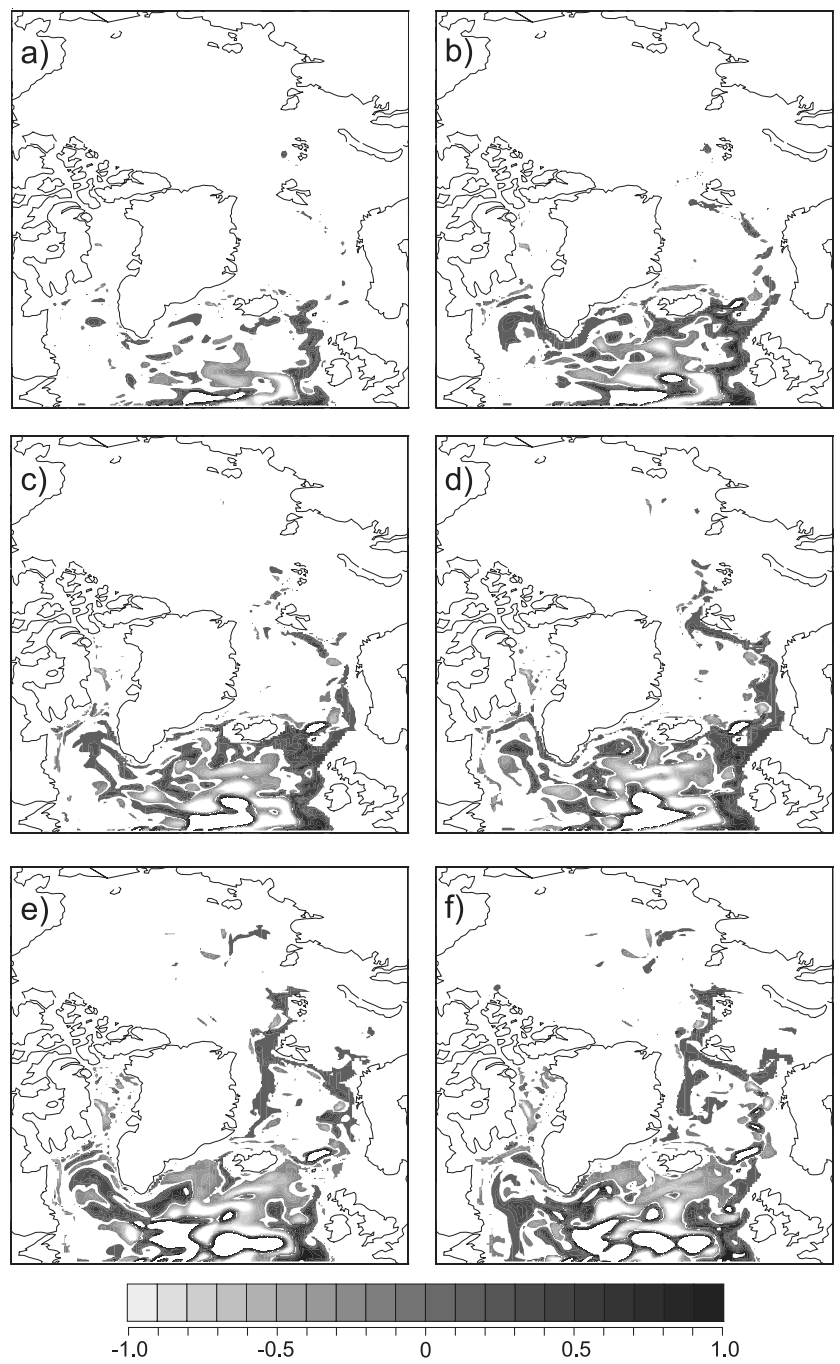

Figure 14. The difference of the temperature $\left[{ }^{\circ} \mathrm{C}\right]$ at $300 \mathrm{~m}$ depth between NAC+SFR and NAC-SFR (a) during summer after half a year, (b) in winter after 1 year, (c) in summer after 1.5 years, (d) in winter after 2 years, (e) in summer after 3.5 years, (f) and in winter after 4 years. Only differences larger than $0.1^{\circ} \mathrm{C}$ in magnitude are displayed. See color version of this figure at back of this issue.

function from the hindcast at the location of the southern boundary of the HRM is also regressed onto the third principal component and added to (subtracted from) the mean stream function at the southern boundary (Figure 13b).

[46] The hydrography at the southern boundary in experiment NAC+SFR is distinguished from the hydrography in experiment NAC-SFR by a shift of the fronts toward the east (Figure 13). The shift of the fronts is accompanied by an increase of the temperature and the salinity at the easternmost part of the southern boundary. The stream function (Figure 13b) has a larger range and the northward flow in the eastern part of the basin becomes broader.

[47] Are these changes, to be imposed on the southern boundary, realistic? A validation of the described changes in the entire water column at the southern boundary is not possible due to a lack of observations. Instead, we use analyses of monthly mean SST compiled from ship obser- vation for the period 1948 to 1993 [da Silva et al., 1994] and calculate the observed area averaged SST anomalies in the SFR (compare Figure 2) for the winter season. The 5 -year running mean (not detrended) and the third principal component from the model show very similar interdecadal variability after applying a 5-year time shift (Figure 13a). The 5-year lag corresponds roughly to the time needed by the SST anomalies to be advected from the SFR to the location of the southern boundary of the HRM. We conclude that the SST anomalies to be imposed at the southern boundary for NAC SFR reflect realistic variability. Because the differences of NAC+SFR and NAC-SFR from NACctrl are almost symmetric, implying a linear response, we will discuss only the differences between NAC+SFR and NAC-SFR.

[48] Half a year after the start of the experiments the temperature above the Iceland-Scotland ridge at $300 \mathrm{~m}$ depth exhibits a difference of $+0.5^{\circ} \mathrm{C}$ (Figure 14a). This anomaly can be traced back to the eastern part of the southern boundary. At the southern boundary we find a tripole structure: a cold anomaly is flanked by two warm anomalies as imposed by the prescribed inflow boundary values (compare Figures 13c-13d). Already half a year later, positive anomalies have emerged in the NwAC and the West Spitsbergen Current (Figure 14b), with mean current velocities of about $10 \mathrm{~cm} / \mathrm{s}$. This corresponds to a translation of about $1500 \mathrm{~km}$ in half a year, consistent with the distance between Spitsbergen and the southern boundary of the model.

[49] The temperature anomalies grow over the years (Figure 14c) and a positive anomaly travels through Fram Strait into the Arctic Ocean (Figure 14d). Two years after the start of the experiment there is a closed band of a positive anomalies from the southern boundary to the Arctic ocean. Yet another 1.5 years later, positive temperature anomalies have evolved in the Barents Sea, next to FranzJoseph Land, in the central Arctic ocean and in the Greenland Sea (Figures $14 \mathrm{e}-14 \mathrm{f}$ ). Simultaneously with the first warm temperature anomalies arriving south of Spitsbergen, a reduction of the sea ice thickness sets in. The spatial pattern is similar to that in the $\mathrm{NAC}+2 \mathrm{~K} 500 \mathrm{~m}$ run (Figure 12), while the thinning is about $50 \%$ smaller.

[50] The warm anomaly takes an easterly and relatively direct way into the Nordic Seas (illustrated as path 1 in Figure 1). At about the same time, a cold anomaly arrives at the Iceland-Scotland ridge (Figures $14 \mathrm{e}-14 \mathrm{f}$ ) from the south. Although originally located close to the warm anomaly at the southern boundary, the cold anomaly takes a much longer way into the Nordic Seas (see path 2 in Figure 1). In the southern part of the NwAC this cold anomaly adds to the warm offset of temperatures from the warm anomaly, leading to a patchy structure in later years.

[51] Simultaneously with the warm anomaly of the first 3 years, a weak positive salinity anomaly passes the Iceland-Scotland-Ridge. However, this signal is completely swamped by the following much larger negative anomaly (Figure 15) which takes a similar path as the cold anomaly described above (path 2 in Figure 1, see Figures 15a-15c and Figure 14). Four years after start of the experiment, a band of anomalously negative salinity extends from the Northeast Atlantic along the Norwegian Coast to the southern parts of Spitsbergen. 


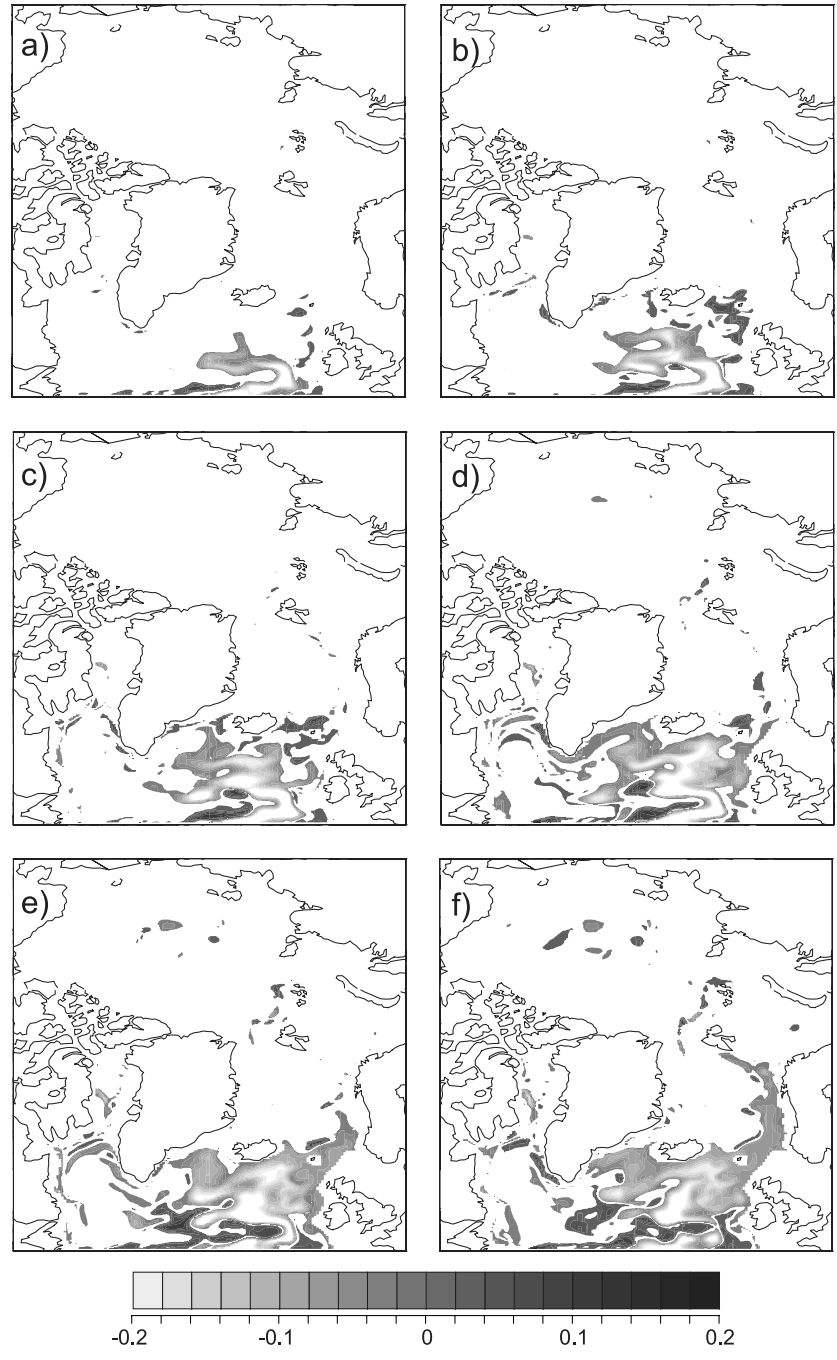

Figure 15. The difference of the salinity [psu] at $300 \mathrm{~m}$ depth between NAC+SFR and NAC-SFR (a) in summer after half a year, (b) in winter after 1 year, (c) in summer after 1.5 years, (d) in winter after 2 years, (e) in summer after 3.5 years, and (f) in winter after 4 years. Only differences larger than $0.02 \mathrm{psu}$ in magnitude are displayed. See color version of this figure at back of this issue.

[52] This results in a warm and fresh anomaly in the northern parts of the NwAC in year 4 after start of the experiment. In ice-free areas, the SSS behaves similarly to the salinity at $300 \mathrm{~m}$ depth. In ice-covered areas, however, strong salinity anomalies are generated by melting ice induced by the warm temperature anomalies.

[53] This behavior is reflected also in the volume, heat, and salt transports across the ridges. Until year 3 they are enhanced across each of both ridges (for NAC+SFR relative to NAC-SFR) by about $0.2 \mathrm{~Sv}, 10 \mathrm{TW}$, and $100-200$ tons/s, respectively. When subsequently the cold and very fresh anomaly enters the ridges the salt transport in NAC+SFR is lower than NAC-SFR by about 300 tons/s across each of the ridges. Interestingly, at this stage the volume transport across the Faroer-Scotland ridge shows no difference between both experiments, while the Iceland-Faroer ridge volume transport of NAC+SFR is increased further to a surplus of almost $0.5 \mathrm{~Sv}$. As a consequence of this larger volume inflow, the heat transport across the Iceland-Faroer ridge is still larger in NAC+SFR, despite the passing of a cold temperature anomaly.

[54] Three years into the experiment, maximal heat content anomalies in box A in the Nordic Sea (compare Figure 3, lag 3) amount to $0.13 \cdot 10^{20} \mathrm{~J}$. This corresponds to a mean temperature anomaly of $0.12^{\circ} \mathrm{C}$. Comparison with the hindcast experiment (compare Figure 4) reveals that these anomalies are about as high as the anomalies imposed by a change of the NAO by one standard deviation. However, the NAO index varies in the range -5 to +5 standard deviations, implying about one order of magnitude larger anomalies than the anomalies generated in experiment NAC_SFR.

[55] On the other hand the change in the mean salinity in box A reaches about -0.03 psu at the end of the experiment. This amplitude is comparable with the amplitudes of anomalies in the hindcast experiment.

\subsection{NCEP_SFR}

[56] The experiments NCEP+SFR and NCEP-SFR are simulations with realistic atmospheric forcing (NCEP/ NCAR reanalysis) and southern boundary conditions as in the previously discussed NAC_SFR experiments. They will serve to assess the fate of the imposed changes in the upstream NAC in relation to the atmospheric variability in the northern North Atlantic and the Nordic Seas. NAC+SFR uses southern boundary conditions typical for the 1960s and NAC-SFR typical for the 1980s. Two 5-year periods are selected (1961-1965 and 1982-1986) for which the experiments NCEP+SFR and NCEP-SFR are performed. The initial conditions for the 5-year experiments are taken from the corresponding years of the hindcast experiment of the HRM with NCEP/NCAR reanalysis forcing [Kauker et al., 2003].

[57] The mean SLP and the ocean currents at $300 \mathrm{~m}$ depth from the hindcast with the HRM for 1961-1965 and the
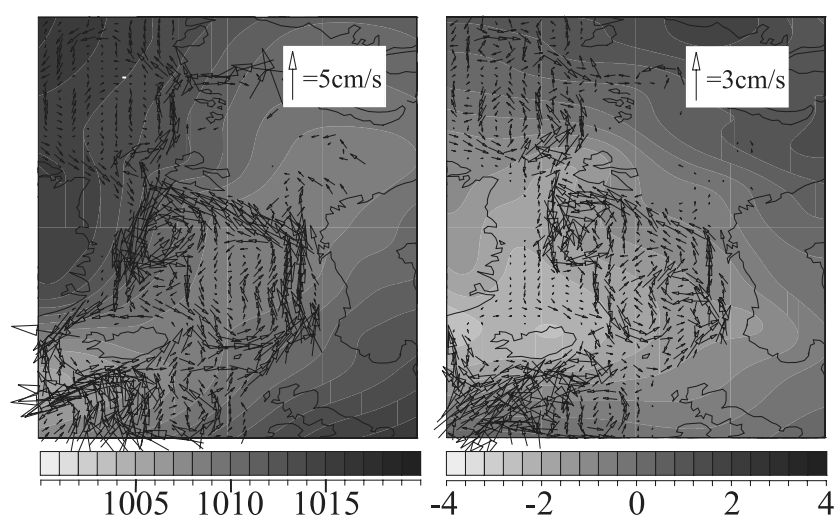

Figure 16. (left) The mean SLP (color) and mean ocean velocity at $300 \mathrm{~m}$ depth of the hindcast with the HRM for the period 1961-1965 and (right) the difference of the SLP and the ocean velocity at $300 \mathrm{~m}$ depth between 1982-1986 and 1961-1965. Note the different scales of the color bars and vectors. See color version of this figure at back of this issue. 


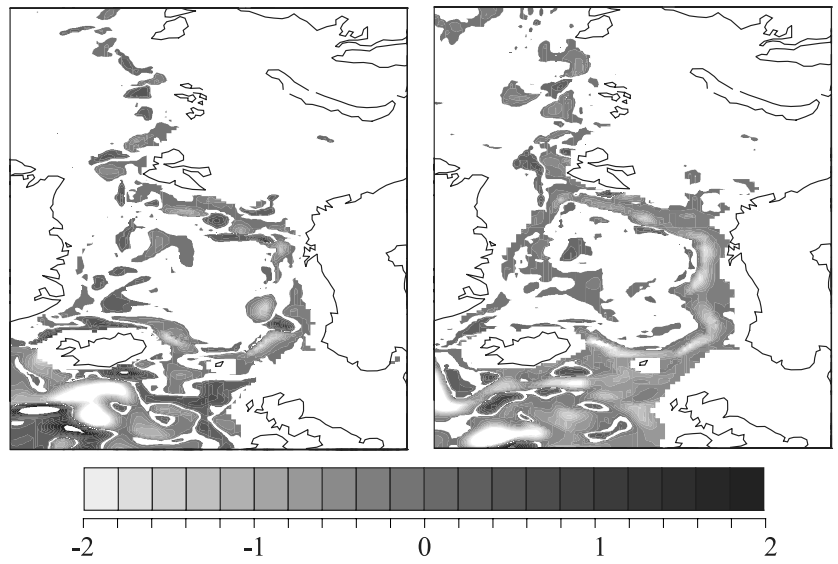

Figure 17. The difference in temperature $\left[{ }^{\circ} \mathrm{C}\right]$ at $300 \mathrm{~m}$ depth between (left) NCEP+SFR and the NCEP/NCAR hindcast in December 1965 (after 4 years integration) and between (right) NCEP-SFR and the NCEP/NCAR hindcast in December 1985 (after 4 years integration). Only differences larger than $0.1^{\circ} \mathrm{C}$ in magnitude are displayed. See color version of this figure at back of this issue.

difference from 1982-1986 are displayed in Figure 16. In the 1982-1986 period the Icelandic low is shifted to the northeast compared to the 1961-1965 period accompanied by reduced inflow south of Iceland and increased transport over the Faroer-Scotland ridge. A more elaborated discussion on the northeastern migration of the Icelandic low and the impacts on the various paths of Atlantic water into the Nordic Seas are given by Nilsen et al. [2003].

[58] NCEP+SFR exhibits a weak and patchy response in the $300 \mathrm{~m}$ depth temperature field in the Nordic Seas (Figure 17, left). In NCEP-SFR, on the other hand, we find a clear and strong negative temperature anomaly outlining the main circulation branches of the Atlantic Water north of the Greenland-Scotland-Ridge (Figure 17, right). This result is consistent only with the early phase of adjustment in the NAC-SFR experiment that employs the same southern boundary values.

[59] This puzzling result can be understood in terms of the pathways of different anomalies. In the 1960s the transport along pathway 2 of Figure 1 is enhanced while the transport along pathway 1 is reduced. Correspondingly, in experiment NCEP+SFR the cold anomaly associated with pathway 2 suppresses the warm anomaly traveling along pathway 1 into the Nordic Seas. In the 1980s the transport along pathway 1 is enhanced while the transport along pathway 2 is reduced. Hence the cold anomaly traveling in experiment NCEP-SFR along pathway 1 has a stronger impact in the Nordic Seas. The anomalies in NCEP-SFR extend further into the Arctic Sea than the anomalies in NAC-SFR. This reflects an enhanced transport along pathway 1 (compare Figures 17 and 14).

[60] The change of the transports between the 1960s and 1980s along pathway 1 and 2 can be assessed from the relative importance of the transports over the two ridges. In the NCAR/NCEP hindcast the mean 1961 to 1965 northward volume transport over the Faroer-Iceland ridge amounts to $3.3 \mathrm{~Sv}$, while for 1982 to 1986 the mean is
3.9 Sv. The northward volume flux over the Iceland-Faroer ridge is almost unchanged during both periods $(3.5 \mathrm{~Sv})$. Northward heat transports (relative to $0^{\circ} \mathrm{C}$ ) across the Scotland-Faroer ridge are $123 \mathrm{TW}$ and $141 \mathrm{TW}$ for 19611965 and 1981-1986, respectively. For the heat transport across the Iceland-Faroer ridge the corresponding numbers are 104 TW and 98 TW.

[61] The enhanced transport in NCEP+SFR along pathway 2 is also visible in the salinity at $300 \mathrm{~m}$ depth (Figure 18, left). The negative salinity anomaly reaches further north into the Arctic Ocean than in experiments NAC_SFR (compare Figure 15f). In experiment NCEPSFR, pathway 1 is preferred and correspondingly a negative anomaly traveling along pathway $1 \mathrm{can}$ be observed.

\section{Summary and Conclusion}

[62] In a series of sensitivity experiments, we identified differences in the propagation characteristics of a set of anomalies imposed on the northward flowing Atlantic Water which enters the Nordic Seas. The results have implications for the interpretation of observations and model experiments and throw light on the predictability of high-latitude ocean state:

[63] 1. Fluctuations of the barotropic transport at the boundary between subtropical and subpolar gyres do not propagate into the Nordic Seas/Arctic Ocean (NAC3psi).

[64] 2. Baroclinic anomalies at that boundary can pass the ridges and enter the Nordic Seas and the Arctic Ocean (NAC $+2 \mathrm{~K} 500 \mathrm{~m}$ ).

[65] 3. The response to realistic southern boundary fluctuations in stream function, temperature, and salinity consists of a complex interaction of anomalies that take different pathways through the subpolar gyre and arrive at the entrance to the Nordic Seas at different times (NAC_SFR).

[66] 4 . During different periods characterized by different atmospheric forcing, the relative contribution of anomalies

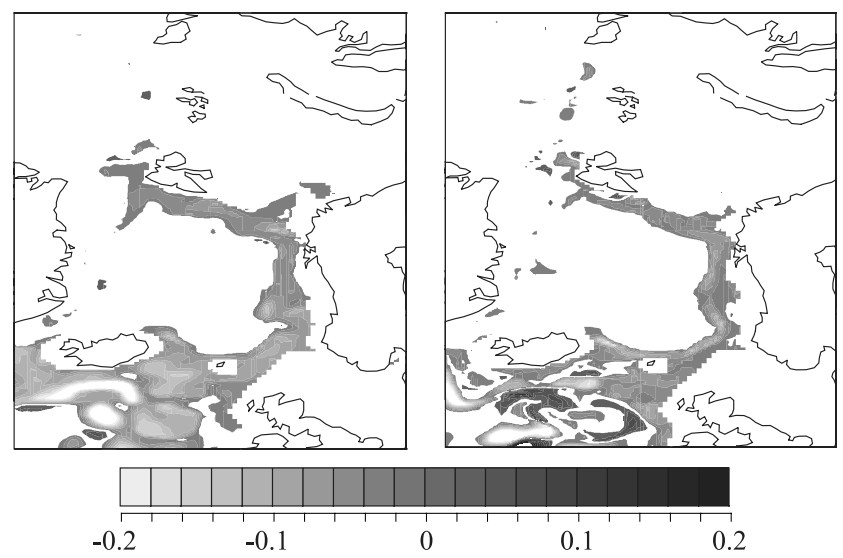

Figure 18. The difference in salinity [psu] at $300 \mathrm{~m}$ depth between (left) NCEP+SFR and the NCEP/NCAR hindcast in December 1965 (after 4 years integration) and between (right) NCEP-SFR and the NCEP/NCAR hindcast in December 1985 (after 4 years integration). Only differences larger than 0.02 psu in magnitude are displayed. See color version of this figure at back of this issue. 
entering across the Faroer-Scotland Ridge and the IcelandFaroer Ridge differs (NCEP SFR).

[67] Signals originating in the North Atlantic influence the hydrography, circulation, and sea ice in the Nordic Seas as long as they not only consist of barotropic transport anomalies. Thus short-term, wind-induced variability will not propagate from the subpolar North Atlantic into the Nordic Seas because the Greenland-Scotland-Ridge presents a large obstacle for flow guided by $f / H$-contours. Owing to the slow propagation speed of baroclinic Rossby waves at these latitudes, variability with timescales of up to several years can be characterized as short-term in this context.

[68] Baroclinic anomalies are less restricted by $\mathrm{f} / \mathrm{H}$ contours and subpolar upper ocean temperature and salinity signals can have a substantial impact on the circulation and hydrography in the Nordic Seas. Anomalies introduced in the North Atlantic near $50^{\circ} \mathrm{N}$ follow distinct pathways to the Nordic Seas that are essentially identical with those identified in hindcast experiments. Thus these paths can be regarded as rather stable. In the case of salinity anomalies, signals of typical amplitude which are advected from the subpolar North Atlantic into the Nordic Seas are comparable in magnitude to the locally induced variability. Advective temperature signals of typical amplitude, i.e., signals of the kind described by Sutton and Allen [1997], are, however, smaller than the anomalies generated by local air-sea heat exchange anomalies. There is a certain potential for prediction of conditions in the Nordic Seas when anomalies in the subpolar gyre or at the boundary between subtropical and subpolar gyres are known. A practical prediction scheme, however, is made difficult by the structure of signals that tend to consist of dipole or tripole signals that might result from shifts in the position of the NAC front or from fluctuations in the width and strength of the current. Anomalies, in general of different sign, originating closely spaced in the vicinity of the NAC usually take different paths through the subpolar Atlantic. The travel time along different paths differs. Still, most of these signals converge again between Faroer and Scotland and follow similar paths through the Nordic Seas. Finally, the resulting signal in the Nordic Seas consists of a sequence of alternating sign anomalies that are difficult to assign to upstream signals.

[69] The signal to noise ratio of predictable anomalies in the Nordic Seas is reduced by the locally generated variability. This is not the case, however, for the Atlantic layer of the Arctic Ocean that is effectively shielded from local atmospheric influences. Given known anomalies in Fram Strait, we expect a larger predictability for these signals propagating into the Arctic Ocean than for signals originating in the North Atlantic.

[70] Acknowledgments. Funding for this project was provided for by the German Ministry for Research and Technology (grant 01 LA 9823) This material is also based upon work partially supported by the National Science Foundation under agreement OPP-0002239 with International Arctic Research Center, University of Alaska, Fairbanks (Arctic Ocean Model Intercomparison Project). The manuscript was finished while RG spent a sabbatical at the Geophysical Fluid Dynamics Laboratory, Princeton. RG thanks GFDL for the hospitality and UCAR for financial support. Thanks to two anonymous reviewers for fruitful comments on the manuscript.

\section{References}

da Silva, A., A. C. Yound, and S. Levitus (1994), NOAA SMD94, Tech. Rep. 6, U.S. Dept. of Comm., Washington, D. C.

Dickson, R. R., J. Meincke, S.-A. Malmberg, and A. J. Lee (1988), The "Great Salinity Anomaly" in the nothern North Atlantic 1968-1982, Progr. Oceanogr., 20, 103-151.

Dickson, R. R., J. Lazier, J. Meincke, P. Rhines, and J. Swift (1996), Longterm coordinated changes in the convective activity of the North Atlantic, Progr. Oceanogr., 38, 241-295.

Environmental Working Group (EWG) (1997), Joint U.S.-Russian Atlas of the Arctic Ocean for the Winter Period [CD-ROM], Natl. Snow and Ice Data Cent., Boulder, Colo.

Furevik, T. (2001), Annual and interannual variability of Atlantic Water temperatures in the Norwegian and Barents Sea: 1980-1996, Deep Sea Res. I, 48, 383-404.

Gerdes, R., C. Köberle, and J. Willebrand (1991), The influence of numerical advection schemes on the results of ocean general circulation models, Clim. Dyn., 5, 211-226.

Gerdes, R., M. Karcher, F. Kauker, and C. Köberle (2001), Predicting the spread of radioactive substances from the Kursk, Eos Trans. AGU, 82(23), 253, 256-257.

Gerdes, R., M. J. Karcher, F. Kauker, and U. Schauer (2003), Causes and development of repeated Arctic Ocean warming events, Geophys. Res. Lett., 30(19), 1980, doi:10.1029/2003GL018080.

Gerdes, R., J. Hurka, M. Karcher, F. Kauker, and C. Koeberle (2005), Simulated history of convection in the Greenland and Labrador seas 1948-2001, in The Nordic Seas: An Integrated Perspective, Geophys. Monogr. Ser., vol. 158, edited by H. Drange et al., pp. 221-238, AGU, Washington, D. C

Gleick, P. H. (1986), Methods for evaluating the regional hdrologic effects of global climate changes, J. Hydrol., 88, 97-116.

Hansen, B., and S. Østerhus (2000), North Atlantic-Nordic Seas exchanges, Progr. Oceanogr., 45, 109-208.

Harder, M., P. Lemke, and M. Hilmer (1998), Simulation of sea ice transport through Fram Strait: Natural variability and sensitivity to forcing, J. Geophys. Res., 103(C3), 5595-5606.

Hibler, W. D. (1979), A dynamic thermodynamic sea ice model, J. Geophys. Res., 9, 815-846.

Hurrell, J. W. (1995), Decadal trends in the North Atlantic Oscillation: Regional temperatures and precipitation, Science, 269, 676-679.

Ingvaldsen, R. B., L. Asplin, and H. Loeng (2004), Velocity field of the western entrance to the Barents Sea, J. Geophys. Res., 109, C03021, doi:10.1029/2003JC001811.

Jones, P. D., T. Jónsson, and D. Wheeler (1997), Extension of the North Atlantic Oscillation using early instrumental pressure observations from Gibraltar and South-West Iceland, Int. J. Climatol., 17, $1433-1450$.

Kalnay, E., et al. (1996), The NCEP/NCAR 40-Year Reanalysis Project, Bull. Am. Meteorol. Soc., 77(3), 437-495.

Karcher, M., R. Gerdes, F. Kauker, and C. Köberle (2003), Arctic warming: Evolution and Spreading of the 1990s warm event in the Nordic Seas and the Arctic Ocean, J. Geophys. Res., 108(C2), 3034, doi:10.1029/ 2001JC001265.

Kauker, F., R. Gerdes, M. J. Karcher, C. Köberle, and J. L. Lieser (2003), Variability of Northern Hemisphere sea ice: A combined analysis of model results and observations from 1978 to 2001, J. Geophys. Res., 108(C6), 3182, doi:10.1029/2002JC001573

Köberle, C., and R. Gerdes (2003), Mechanisms determing variability of Arctic ice conditions and export, J. Clim., 16, 2843-2858.

Levitus, S., R. Burgett, and T. Boyer (1994), World Ocean Atlas 1994, U.S. Dept. of Comm., Washington, D. C.

Mauritzen, C. (1996), Production of dense overflow waters feeding the North Atlantic across the Greenland-Scotland Ridge, Deep Sea Res., $43,769-835$

Nilsen, J. E. A., Y. Gao, H. Drange, T. Furevik, and M. Bentsen (2003), Simulated North Atlantic-Nordic Seas water mass exchanges in an isopycnic coordinate OGCM, Geophys. Res. Lett., 30(10), 1536, doi:10.1029/2002GL016597.

North, G. R., T. L. Bell, R. F. Cahalan, and F. J. Moeng (1982), Sampling errors in the estimation of empirical orthogonal function, Mon. Weather Rev. 110, 699-706.

Orvik, K. A., and O. Skagseth (2003), The impact of the wind stress curl in the North Atlantic on the Atlantic inflow to the Norwegian Sea towards the Arctic, Geophys. Res. Lett., 30(17), 1884, doi:10.1029/ 2003GL017932.

Pacanowski, R. C. (1995), MOM 2 documentation, user's guide and reference manual, GFDL Ocean Group Tech. Rep. 3, Geophys. Fluid Dyn. Lab., Princeton Univ., Princeton, N. J.

Röske, F. (2001), An atlas of surface fluxes based on the ECMWF reanalysis-A climatological data set to force global ocean general circula- 
tion models, MPI Rep. 323, Max-Planck-Inst. für Meteorol., Hamburg, Germany.

Saloranta, T. M., and P. M. Haugan (2001), Interannual variability in the hydrography of Atlantic Water northwest of Svalbard, J. Geophys. Res., 106, 13,931-13,943

Stevens, D. P. (1991), On open boundary condition in the United Kingdom Fine-Resolution Antarctic Model, J. Phys. Oceanogr., 21, $1494-1499$.

Sutton, R. T., and M. R. Allen (1997), Decadal predictability of North Atlantic sea surface temperature and climate, Nature, 388, 563-567.
Timlin, M. S., M. A. Alexander, and C. Deser (2002), On the reemergence of North Atlantic SST anomalies, J. Clim., 15(18), 2707-2712.

Zalesak, S. T. (1979), Fully multidimensional flux-corrected transport algorithms for fluids, J. Comput. Phys., 31, 335-362.

R. Gerdes, M. Karcher, F. Kauker, and C. Köberle, Alfred Wegener Institute for Polar and Marine Research, P. O. Box 120161, D-27515 Bremerhaven, Germany. (fkauker@awi-bremerhaven.de) 

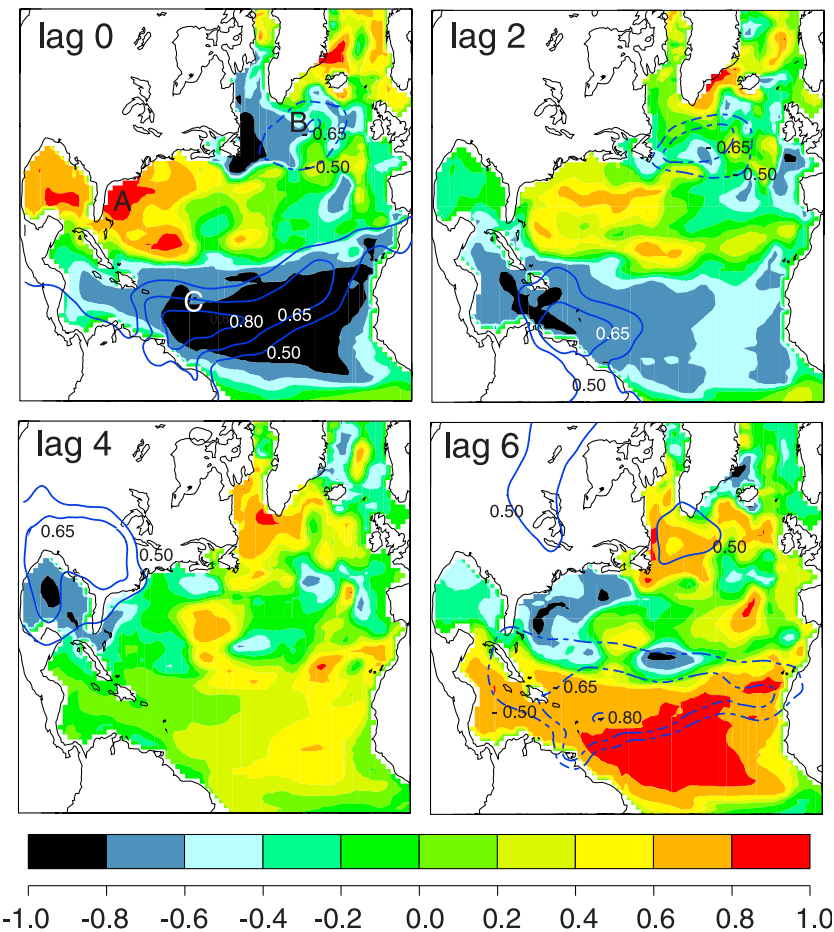

Figure 2. The amount of low-frequency variability of local sea-surface temperature (SST) and sea-level pressure (SLP) that can be accounted for as a linear response to the SST off the coast of Florida. The SST off the coast of Florida leads the local SST and the local SLP by the amount of years indicated in each panel. The contour lines shown for the SLP regression are for $\pm 0.50, \pm 0.65$, and \pm 0.80 . Dashed lines indicate negative correlations. Note the locations "A" off Florida in the upper left panel (see text).
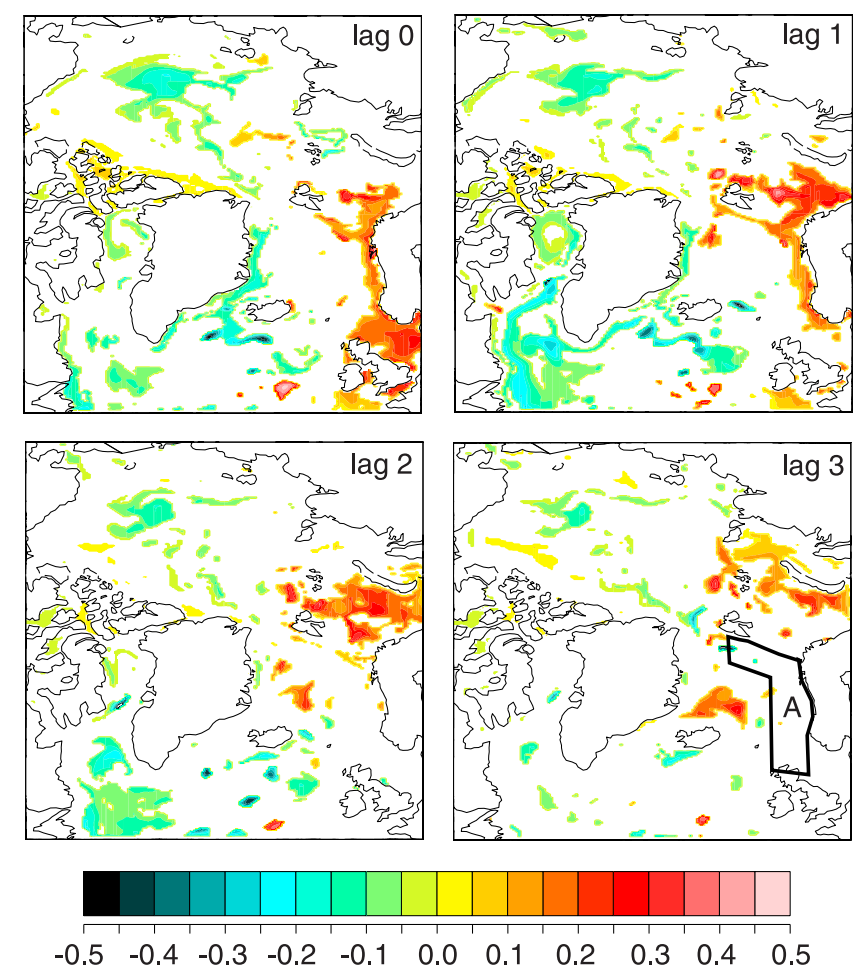

Figure 3. The averaged temperature $\left[{ }^{\circ} \mathrm{C}\right]$ of the upper $300 \mathrm{~m}$ water column which can be accounted for as a linear response to the NAO. The NAO leads the local temperature by the amount of years shown in each plot. Only significant (correlation coefficient higher than 0.4) slope coefficients are displayed. Note the locations of box "A" off the Norwegian coast and south of Spitsbergen in the lower right panel (see text). 

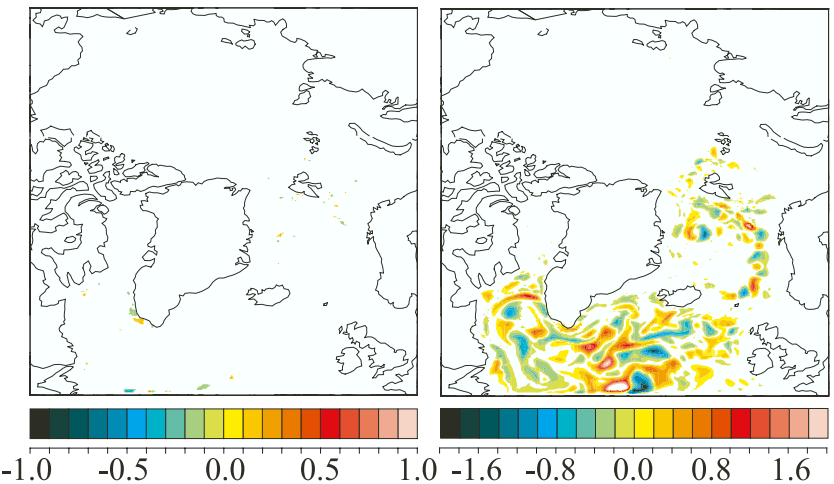

Figure 6. The temperature difference $\left[{ }^{\circ} \mathrm{C}\right]$ between NACctrlld and NACctrl at $300 \mathrm{~m}$ depth (left) after 5 months and (right) after 5 years of integration. Only differences larger than $0.1^{\circ} \mathrm{C}$ in magnitude are displayed. Note the different scales of the color bars.
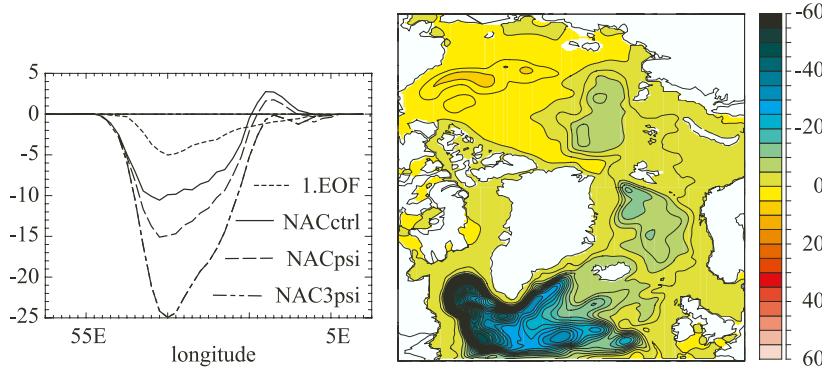

Figure 7. The mean state (right panel and the solid line in the left panel) of the barotropic stream function $[\mathrm{Sv}]$ in the control run and the first EOF (left panel short-dashed line) of the stream function at the southern boundary deduced from the NCEP/NCAR hindcast experiment with the LRM. Also the stream function at the southern boundary in experiment NACpsi (long-dashed line) and the experiment NAC3psi (long-short-long dashed line) are shown in the left panel.

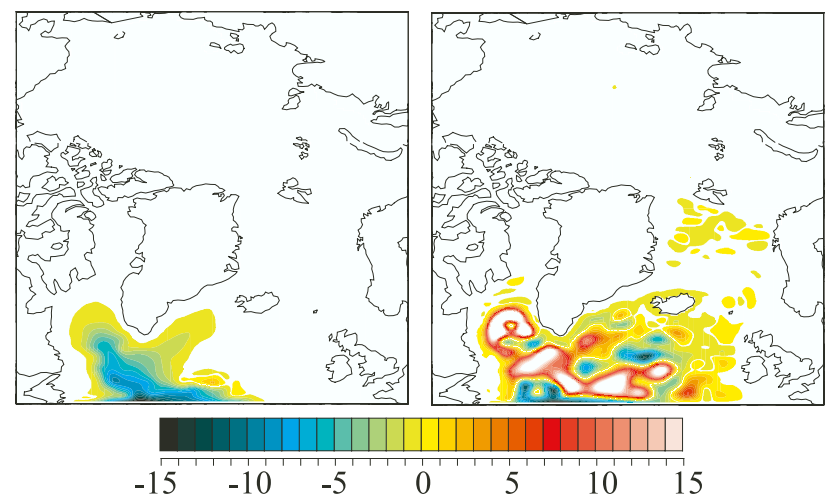

Figure 8. The difference of the stream function [Sv] between NAC3psi and NACctrl after 1 month (left) and after 5 years (right). Only differences larger than $0.1 \mathrm{~Sv}$ in magnitude are displayed.
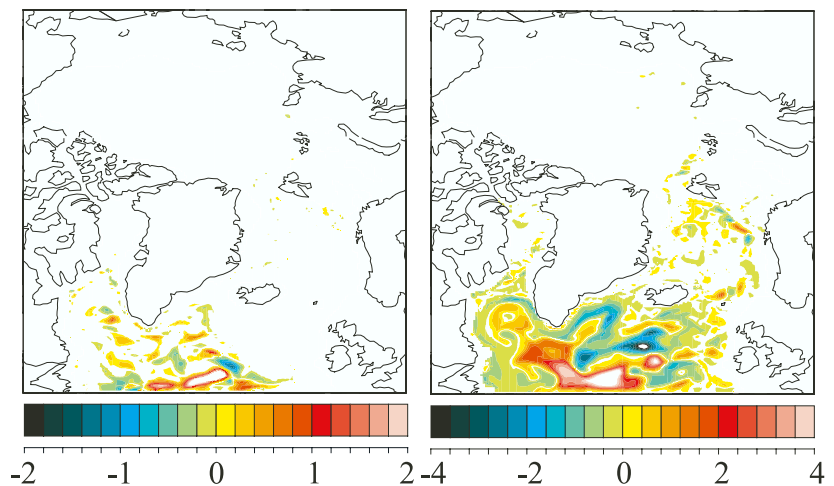

Figure 9. The difference of the temperature $\left[{ }^{\circ} \mathrm{C}\right]$ at $300 \mathrm{~m}$ depth between NAC3psi and NACctrl after 5 months (left) and after 5 years (right). Only differences larger than $0.1^{\circ} \mathrm{C}$ in magnitude are displayed. Note the different scales of the color bars. 


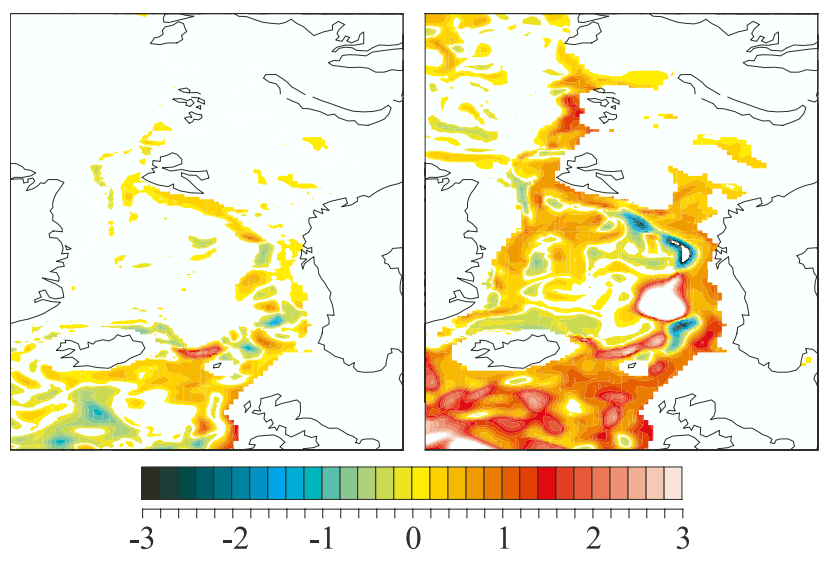

Figure 10. The difference of the temperature $\left[{ }^{\circ} \mathrm{C}\right]$ at $300 \mathrm{~m}$ depth between NAC $+2 \mathrm{~K} 500 \mathrm{~m}$ and NACctrl after 2 years (left) and after 5 years (right). Only differences larger than $0.1^{\circ} \mathrm{C}$ in magnitude are displayed.
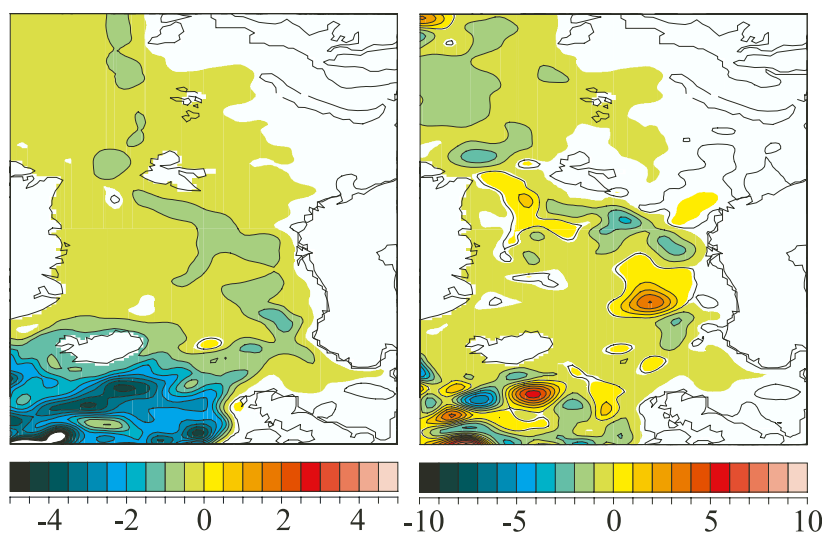

Figure 11. The difference of the stream function $[\mathrm{Sv}]$ for the vertically integrated volume transport between $\mathrm{NAC}+2 \mathrm{~K} 500 \mathrm{~m}$ and NACctrl (left) after 2 years and (right) after 5 years. Only differences larger than $0.1 \mathrm{~Sv}$ in magnitude are displayed. Additionally, on the left panel contours with an interval of $0.5 \mathrm{~Sv}$ and on the right panel with $1 \mathrm{~Sv}$ are plotted. Note the different scales of the color bars. 


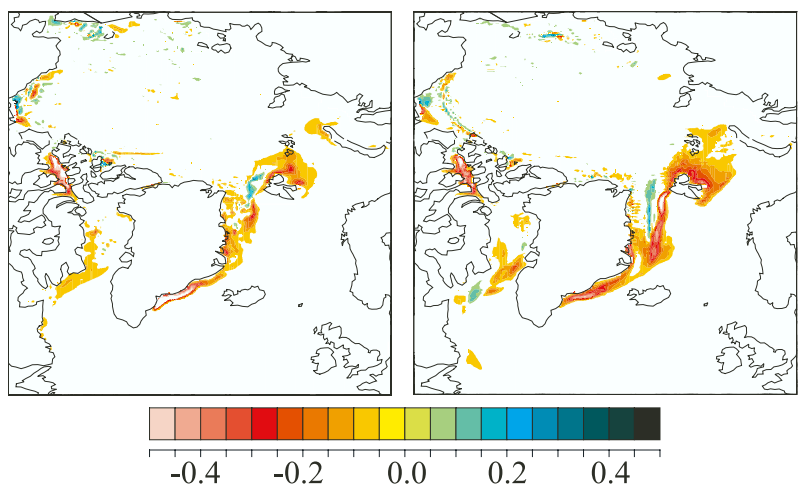

Figure 12. The difference in ice thickness $[\mathrm{m}]$ between $\mathrm{NAC}+2 \mathrm{~K} 500 \mathrm{~m}$ and NACctrl in summer after 4.5 years (left) and in the following winter. Only differences larger than $0.05 \mathrm{~m}$ in magnitude are displayed. a)

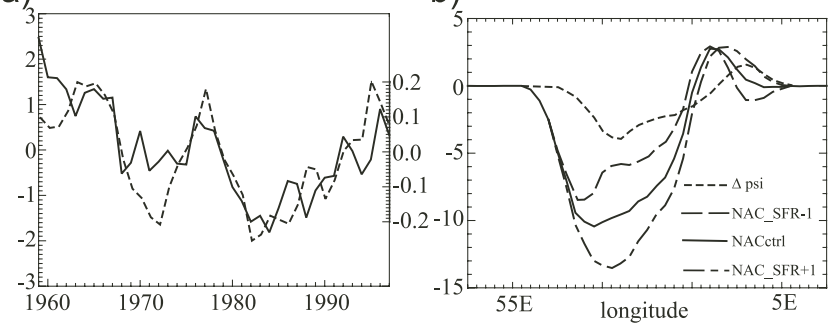

c)

C)

d)

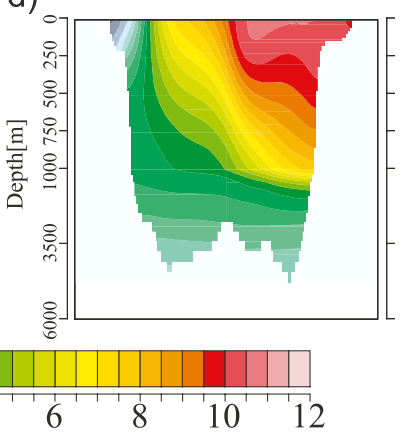

e)

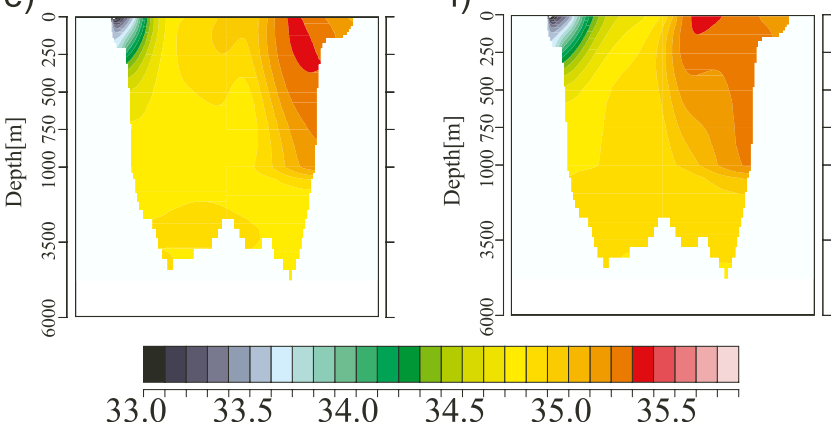

Figure 13. (a) The third principal component (solid line, left axis labels) of the heat transport in a corridor between Iceland and Scotland. Additionally, the time series of the winter-centered yearly mean observed SST $\left[{ }^{\circ} \mathrm{C}\right]$ in the SFR is shown (dashed line, right axis labels). The SFR time series is filtered with a 5 -year running mean and shifted in time by 5 years, i.e., values from 1955 to 1993 are plotted, accounting for the travel time of the temperature signals. (b) The stream function for the experiments NAC+SFR and NAC-SFR and in the control run is shown [Sv]. The remaining panels show distributions at the southern boundary of the HRM of (c) temperature $\left[{ }^{\circ} \mathrm{C}\right]$ in experiment NAC+SFR, (d) NAC-SFR, (e) salinity [psu] in experiment $\mathrm{NAC}+\mathrm{SFR}$, and (f) NAC-SFR. 

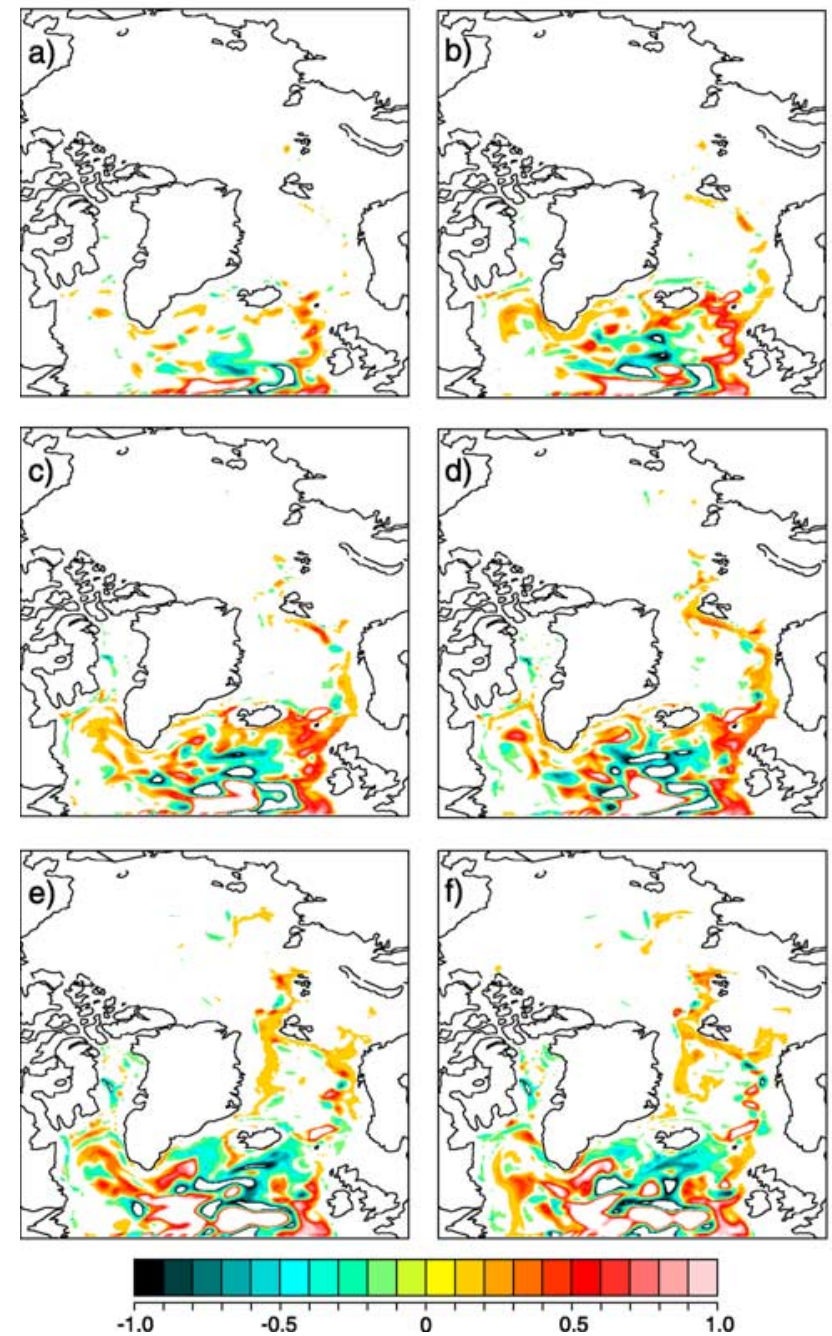

Figure 14. The difference of the temperature $\left[{ }^{\circ} \mathrm{C}\right]$ at $300 \mathrm{~m}$ depth between NAC+SFR and NAC-SFR (a) during summer after half a year, (b) in winter after 1 year, (c) in summer after 1.5 years, (d) in winter after 2 years, (e) in summer after 3.5 years, (f) and in winter after 4 years. Only differences larger than $0.1^{\circ} \mathrm{C}$ in magnitude are displayed. 

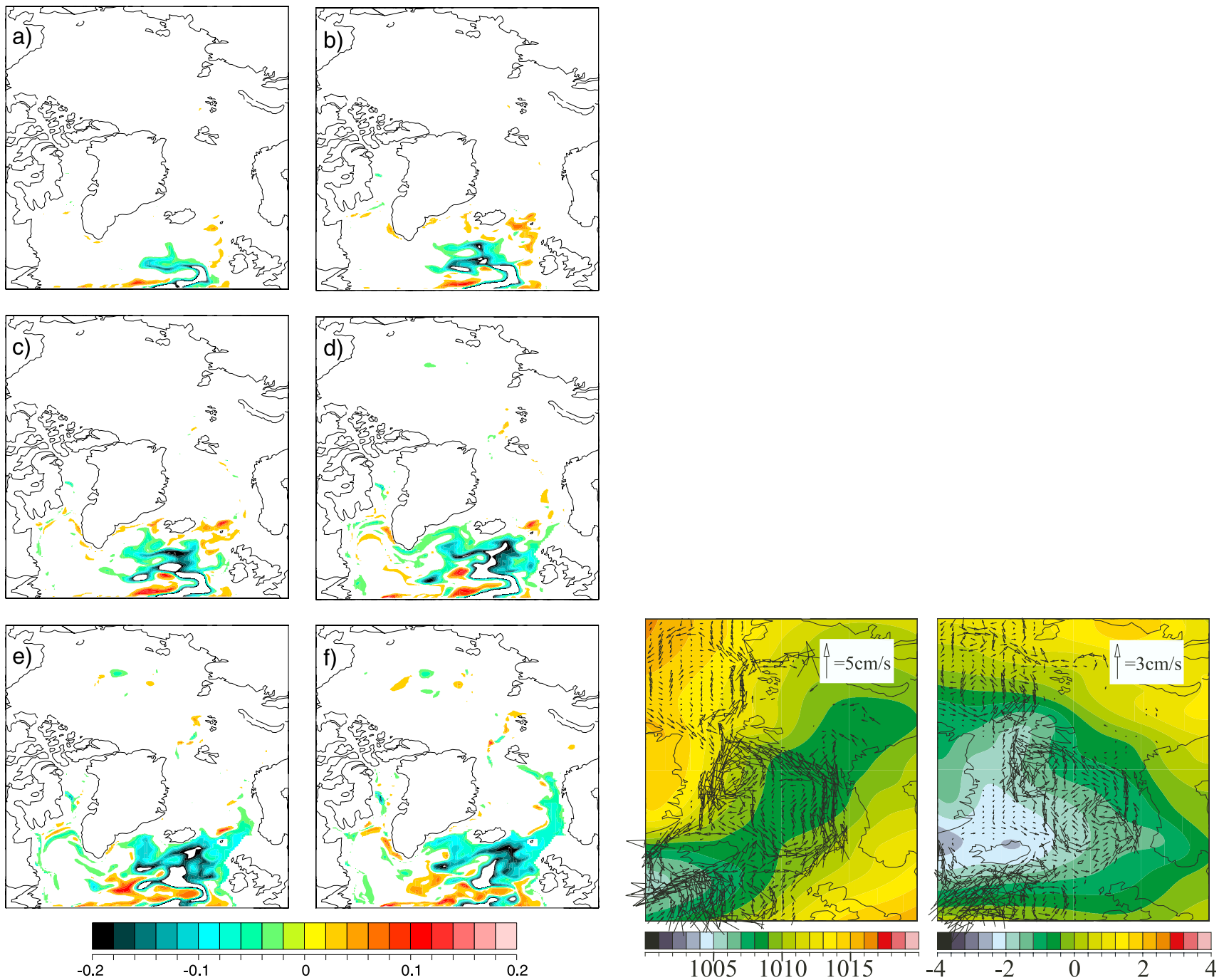

Figure 15. The difference of the salinity [psu] at $300 \mathrm{~m}$ depth between NAC+SFR and NAC-SFR (a) in summer after half a year, (b) in winter after 1 year, (c) in summer after 1.5 years, (d) in winter after 2 years, (e) in summer after 3.5 years, and (f) in winter after 4 years. Only differences larger than $0.02 \mathrm{psu}$ in magnitude are displayed.

Figure 16. (left) The mean SLP (color) and mean ocean velocity at $300 \mathrm{~m}$ depth of the hindcast with the HRM for the period 1961-1965 and (right) the difference of the SLP and the ocean velocity at $300 \mathrm{~m}$ depth between $1982-1986$ and 1961-1965. Note the different scales of the color bars and vectors. 

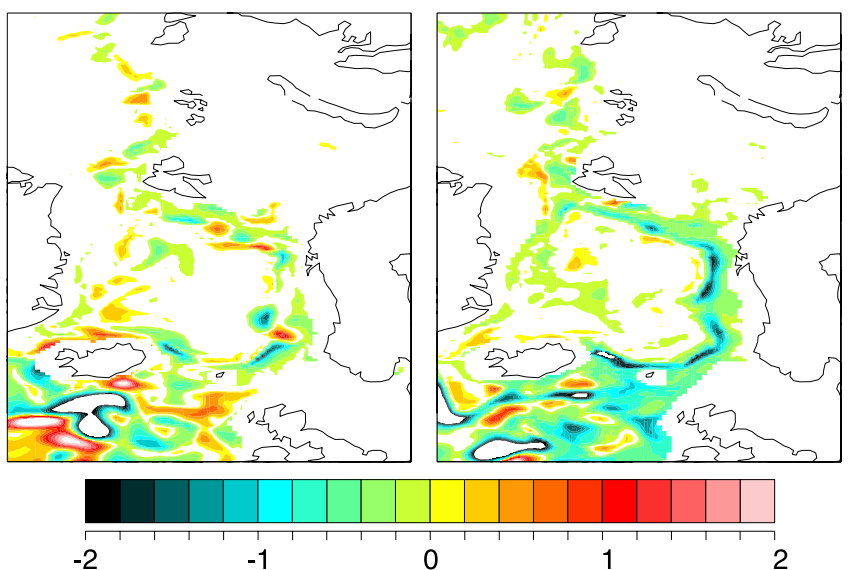

Figure 17. The difference in temperature $\left[{ }^{\circ} \mathrm{C}\right]$ at $300 \mathrm{~m}$ depth between (left) NCEP+SFR and the NCEP/NCAR hindcast in December 1965 (after 4 years integration) and between (right) NCEP-SFR and the NCEP/NCAR hindcast in December 1985 (after 4 years integration). Only differences larger than $0.1^{\circ} \mathrm{C}$ in magnitude are displayed.

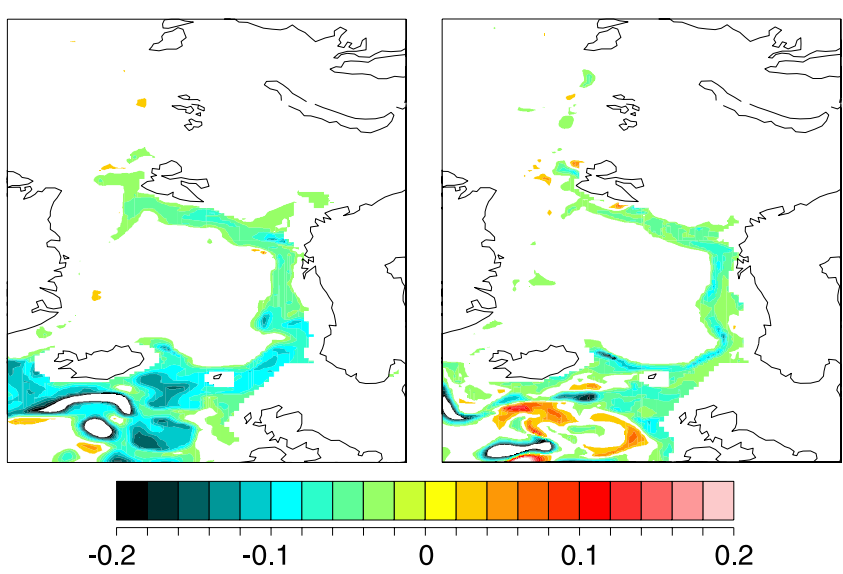

Figure 18. The difference in salinity [psu] at $300 \mathrm{~m}$ depth between (left) NCEP+SFR and the NCEP/NCAR hindcast in December 1965 (after 4 years integration) and between (right) NCEP-SFR and the NCEP/NCAR hindcast in December 1985 (after 4 years integration). Only differences larger than $0.02 \mathrm{psu}$ in magnitude are displayed. 